\title{
LAS CERÁMICAS IBÉRICAS CON DECORACIÓN IMPRESA DE ALARCOS (Ciudad Real)
}

\section{Iberian Ceramics with Imprinted Decoration from Alarcos (Ciudad Real)}

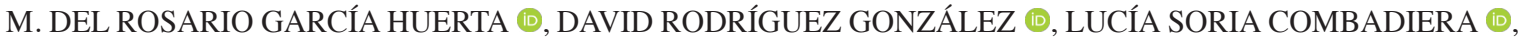 FRANCISCO JAVIER MORALES HERVÁS (D}

Dpto. de Historia. Universidad de Castilla-La Mancha.

Rosario.Garcia@uclm.es, David.Rodriguez@uclm.es, lucia.soria@uclm.es,Fco.Morales@uclm.es

RESUMEN:

Se presenta un conjunto de cerámicas ibéricas con decoración impresa procedentes del oppidum de Alarcos (Ciudad Real). Se analizan formas, decoraciones, calidades y contextos y se aportan elementos para la reflexión sobre estas cerámicas de presencia minoritaria, en relación con otras producciones iberas, y de excelente manufactura.

Palabras clave: II Edad del Hierro, Cultura Ibérica, cerámica, decoración impresa, estampillas.

Abstract:

We are presenting a group of Iberian pottery pieces with imprinted decoration coming from the oppidum of Alarcos (Ciudad Real). We will focus on shapes, decorations, quality, and contexts. The paper also offers evidences for a reflection on these potteries, the minority presence of this type of decoration, along with the relation with other productions, and the excellent quality that it usually presents.

Key words: $2^{\text {nd }}$ Iron Age, Iberian culture, pottery, imprinted decoration, stamps. 
Prácticamente desde la invención de la cerámica los artesanos alfareros ya mostraron su tendencia a ornamentar una parte considerable de sus producciones con diferentes motivos decorativos, entre los que presentaban un cierto protagonismo los motivos impresos. La existencia de cerámicas con decoración impresa y/o estampillada en yacimientos de época ibérica, no debe ser considerada como el resultado de una tendencia aislada dentro de la Prehistoria Reciente, de hecho, se trata de un fenómeno conocido desde hace décadas (Cura 1971 y 1975; Lillo 1977-78; Ruiz y Nocete 1981, entre otros autores). Su presencia, a pesar de no ser destacada cuantitativamente, ha llamado la atención a numerosos investigadores que han realizado estudios tanto concretos, como el de Pinta (1993) centrado sobre todo en el área barcelonesa, y el de Martí (1994) para Arse/Saguntum (Valencia), como globales sobre este tipo de decoración que aparece bien representada en diversos ámbitos de la geografía peninsular en la II Edad del Hierro: Meseta, Noroeste, Valle del Guadalquivir, La Mancha y litoral mediterráneo (Lillo 1977-1978).

El territorio correspondiente a la denominada Oretania Septentrional ha sido uno de los que ha aportado un mayor número de yacimientos en los que se han documentado cerámicas con decoración impresa y estampillada, hasta el punto de poder afirmar que esta decoración representa una de las características más significativas de la cerámica ibérica documentada en buena parte de la provincia de Ciudad Real y el extremo occidental de Albacete. Los grandes oppida de la zona (Cerro de las Cabezas, Oreto, la Bienvenida o Libisosa) cuentan con buenos repertorios que han sido objeto de estudios más o menos específicos (Vélez y Pérez 1987; Nieto et al. 1980; Esteban Borrajo 2000; Fernández Maroto et al. 2007; Uroz Rodríguez 2012).

El poblamiento de la Oretania Septentrional responde a unos claros patrones de jerarquización estructurándose el hábitat a partir de grandes oppida como Alarcos que controlarán amplios territorios de más de 30 km de diámetro en los que se localizan otros asentamientos de menor entidad (Morales 2010). Estos poblados van a compartir una misma estrategia productiva en la que tendrá un papel destacado la producción de excedentes con el fin de comerciar con ámbitos foráneos, lo cual se pone de manifiesto a través de la documentación de destacados productos exógenos como cerámicas áticas (García Huerta et al. 2004: 115-130). Además, también existirá una producción pensada para el intercambio interno del área controlada por cada asentamiento principal en el que es característica la producción cerámica decorada con motivos geométricos pintados que, en ocasiones, aparece complementada por motivos estampillados, que son los que centran el presente estudio.

El asentamiento de Alarcos se encuentra dentro de la región que los autores clásicos denominaron Oretania, un espacio localizado entre los valles de los ríos Guadiana y Guadalquivir, contando como zona nuclear, en torno a la cual se configuran los pueblos oretanos, el eje montañoso de Sierra Morena, que constituirá una auténtica columna vertebral con un gran interés económico (minería), estratégico (vías de comunicación) y religioso (santuarios). A partir de esta zona central podemos delimitar grosso modo el ámbito oretano tomando en consideración, y con las debidas cautelas, los datos que aportan las fuentes clásicas, básicamente Estrabón en su Geografía (III, 1 al 4), Ptolomeo en sus Tablas (II, 6), y Plinio en su Historia Natural (III, 19 y 25). En líneas generales, la Oretania comprendería buena parte del espacio que actualmente ocupan las provincias de Ciudad Real y Jaén y una pequeña parte de la de Albacete.

El yacimiento de Alarcos (fig. 1) se eleva unos $100 \mathrm{~m}$ sobre el valle del río Guadiana, lo que le proporciona un privilegiado control visual sobre un amplio espacio de gran interés agrario, cinegético y minero. Cuenta con tres fases de ocupación bien definidas: una fase del Bronce Final-Hierro I, una ibérica y otra medieval. La ocupación medieval no fue muy prolongada, pero resultó de gran interés al corresponder a una fase de construcción de una notable ciudad cristiana, cuyo proceso quedaría cercenado por la derrota de Alfonso VIII frente a los almohades en la Batalla de Alarcos de 1195. El proceso de construcción de la ciudad medieval alteró de forma muy significativa los niveles ibéricos y preibéricos, que se vieron muy afectados, lo cual, además de los lógicos procesos postdeposicionales, explica que resulte muy complicado encontrar niveles ibéricos intactos y ello conlleva que la inmensa mayoría del material cerámico aparezca muy fragmentado, lo cual dificulta la definición de formas y decoraciones. En el Sector III nos encontramos este condicionante al que se suma la documentación de un gran almacén ibérico de grano y área de molienda y horneado (García Huerta et al. 2006), cuya edificación también afectó al hábitat ibérico y preibérico precedentes.

Aunque contamos con referencias a la importancia del yacimiento de Alarcos desde finales del s. XIX, no será hasta los años ochenta del pasado siglo cuando se inicien las excavaciones sistemáticas, que, prácticamente sin interrupción, se han mantenido hasta la actualidad. El cerro de Alarcos, que ocupa una superficie de unas 30 has, fue 


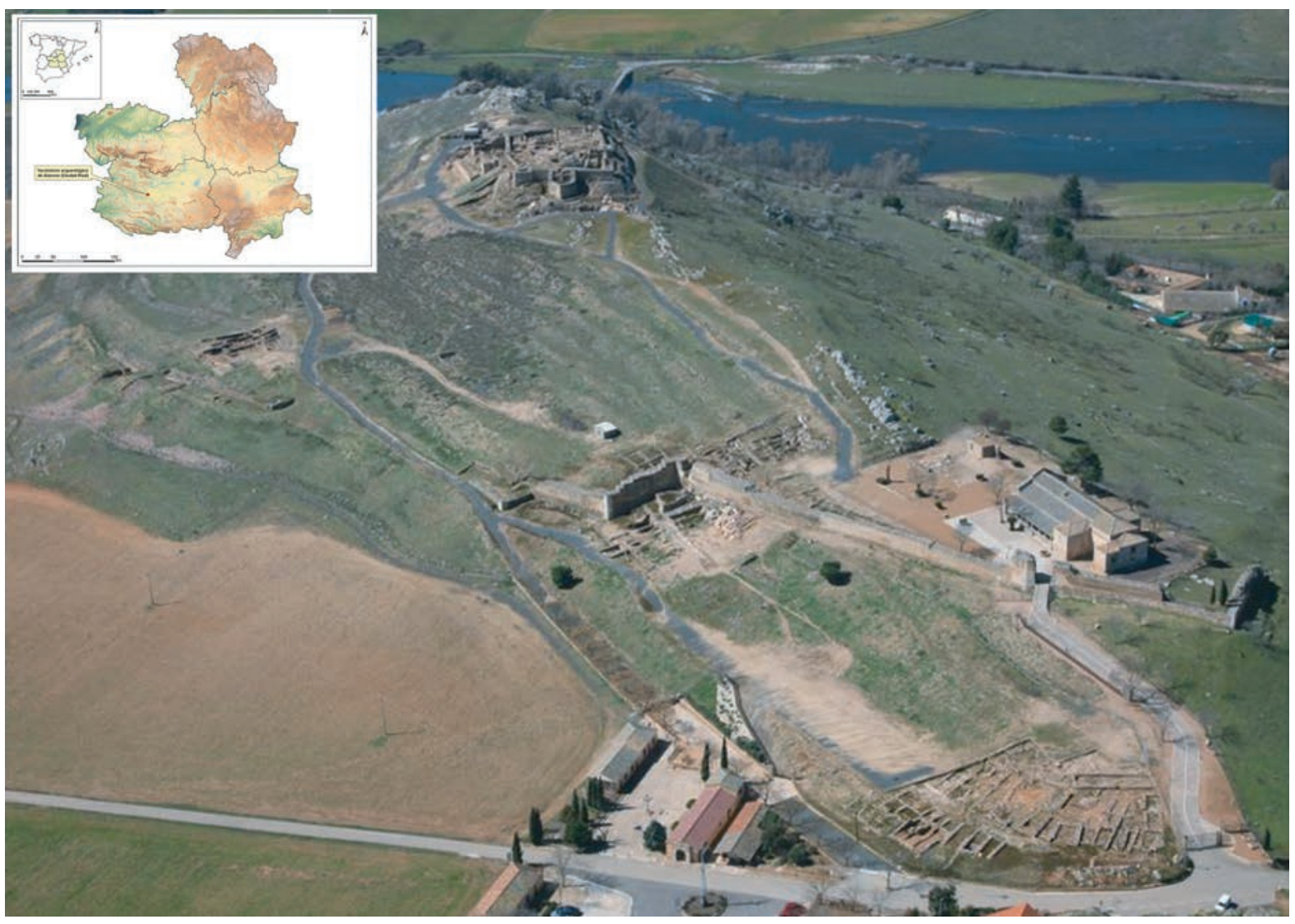

Fig. 1: Plano de situación y vista del cerro de Alarcos.

topografiado y dividido en 4 sectores para favorecer la organización de los trabajos arqueológicos. Hasta la fecha la mayor parte de las intervenciones se han centrado en el Sector IV y en la zona de la Alcazaba, además del Sector III, área investigada por nosotros desde 1997 y de donde proceden los materiales analizados en este estudio. Los trabajos desarrollados en esta zona han permitido documentar una muestra significativa de cerámicas estampilladas que se une a las ya conocidas con anterioridad en otras zonas del yacimiento y que han sido previos (Morales 1993).

\section{LAS CERÁMICAS IBÉRICAS IMPRESAS DEL SECTOR III DE ALARCOS}

En el cerro de Alarcos la presencia de cerámicas con decoración impresa está documentada desde mediados del s. XX (Gil Farrés 1952) y en todas las campañas arqueológicas que se han desarrollado en este yacimiento desde los años 80 del s. XX se han recuperado nuevos restos con este peculiar tipo de decoración. El porcentaje de cerámica con motivos impresos o estampillados de Alarcos, en relación con el total de cerámica decorada, sigue la pauta general de los datos aportados por otros yacimientos de la Oretania septentrional, incluso de otras zonas como la andaluza y la valenciana (Ruiz y Nocete 1981: 356), donde apenas supera el 4\% (Morales 1993: 192).

En el área estudiada, el Sector III Universidad (figs. 2 y 3), se han contabilizado en total 58 fragmentos de cerámicas con decoración impresa. La mayoría proceden de dos viviendas de época ibérica, situadas próximas a un almacén de grano (García Huerta y Morales 2009: 174-181). Estas construcciones se encuentran muy alteradas por la posterior ocupación medieval, de tal manera que no hemos podido completar su planta ni obtener fechas absolutas, si bien nos inclinamos hacia cronologías algo más recientes que la del almacén de grano. Nuestras excavaciones se han centrado en el citado almacén, donde el número de cerámicas con decoración impresa es muy bajo, mientras que los trabajos en el área de habitación ibérica, a pesar de encontrarse en 


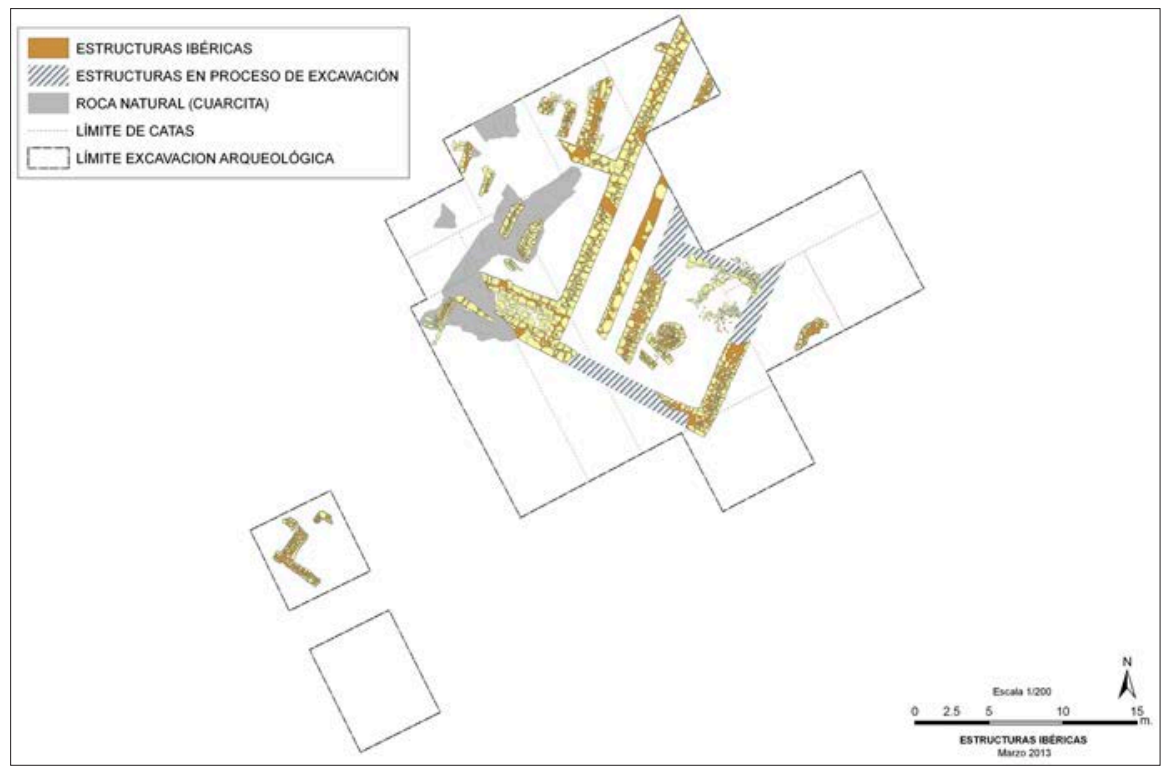

Fig. 2: Plano del Sector III de Alarcos con las estructuras ibéricas.

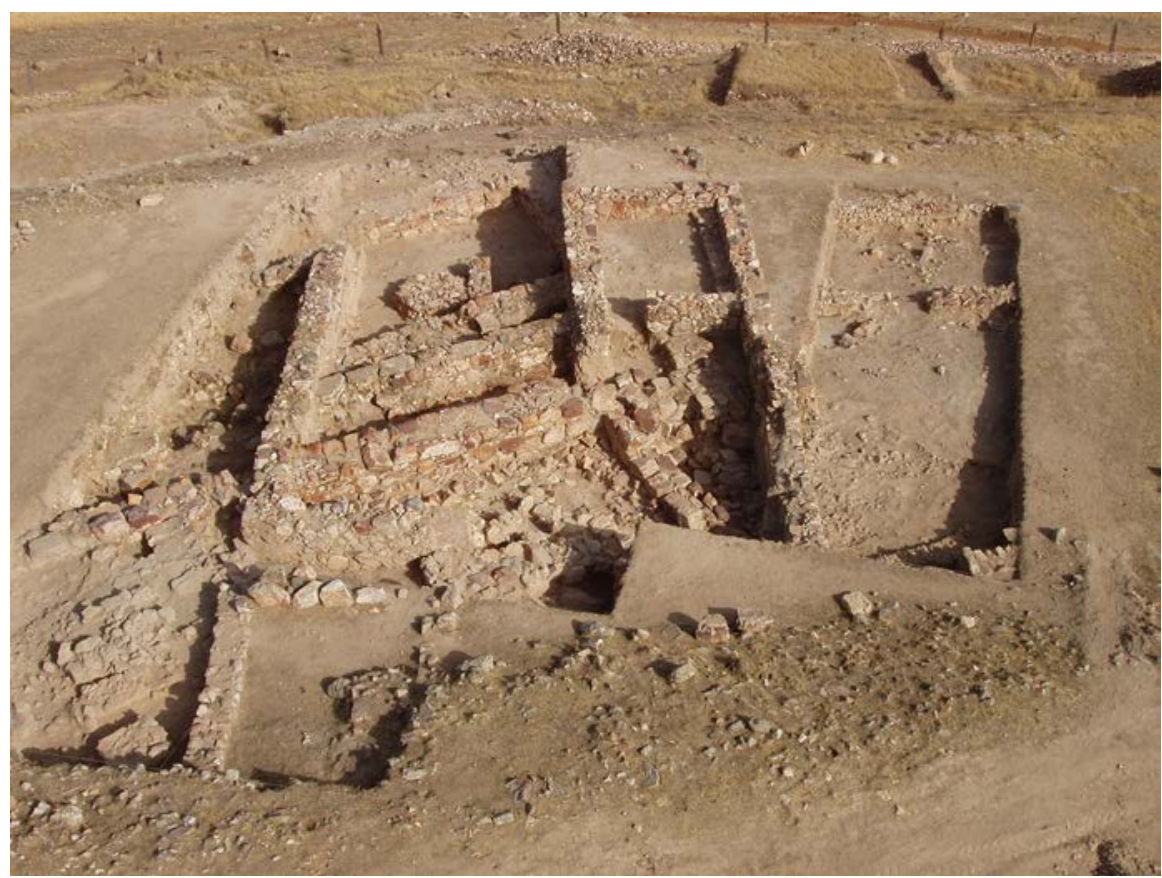

Fig. 3: Vista del almacén de grano ibérico de Alarcos.

una etapa inicial, están ofreciendo un porcentaje más alto de estas producciones. Las fechas de C-14 obtenidas del almacén lo sitúan en el s. IV a. C. con posible perduración hasta el III a.C. No disponemos de fechas absolutas de las construcciones ibéricas excavadas, sin embargo, el hallazgo de cerámicas impresas en la necrópolis de Alarcos (García Huerta et al. 2018) fechada a partir del s. III a.C. abogaría por una cronología similar.

\section{LAS CALIDADES}

Todas las cerámicas que incluimos en este estudio son a torno y pertenecen a la Clase A o cerámica fina, excepto una (AL11-U19-6-97), 43 ejemplares tienen las pastas claras u oxidantes $(74,1 \%)$ y el resto de cerámica gris $(25,9 \%)$. Las cerámicas de pastas claras tienen buena calidad, con desgrasantes minerales muy finos casi 


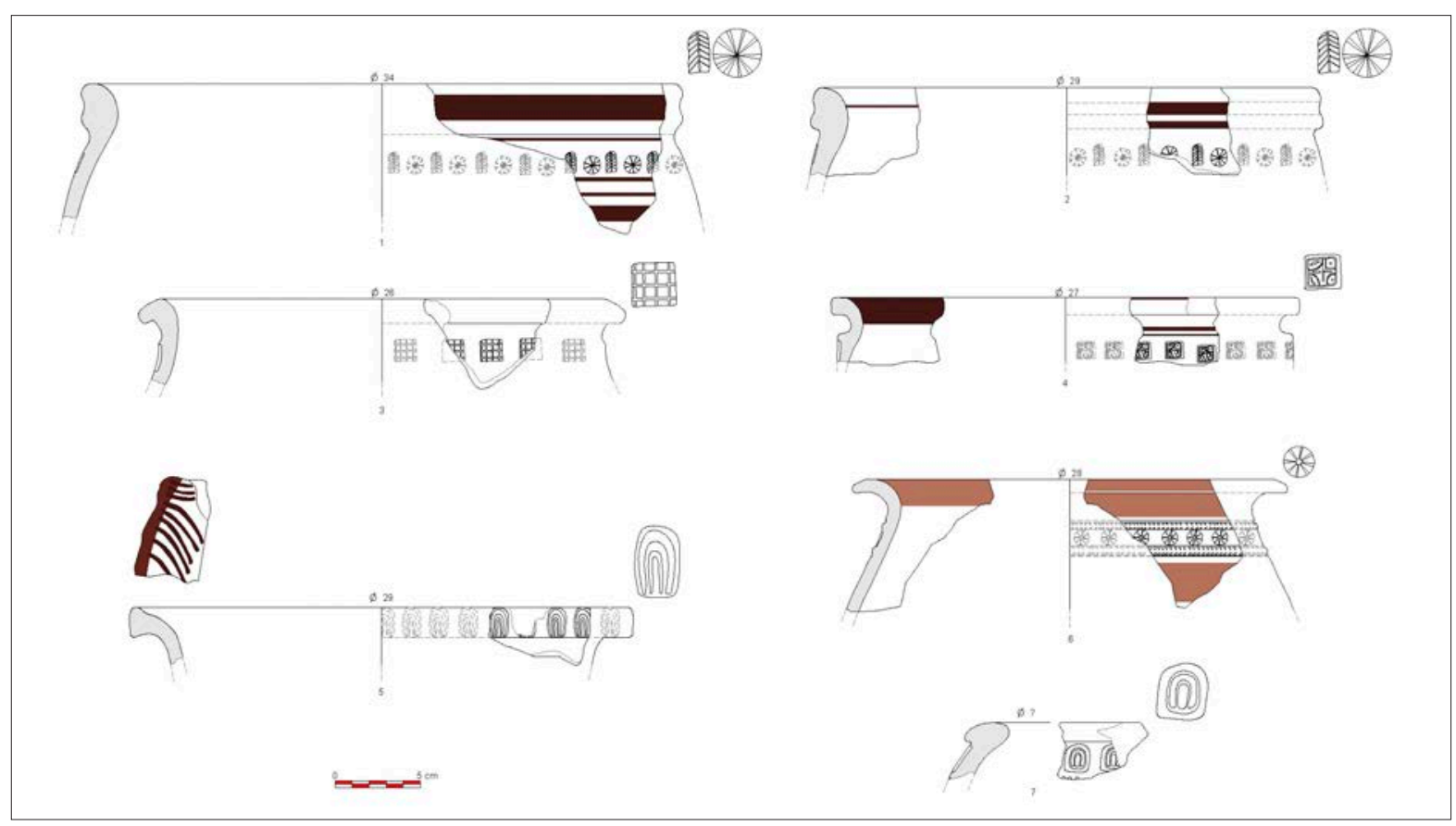

Fig. 4: Recipientes de almacenaje y despensa: 1 y 2: Orzas; 3, 5 y 6: Tinajas; 4: Tarro; 7: Tinaja o tinajilla.

inapreciables. Presentan una cocción homogénea, oxidante, estimada entre $900-950^{\circ} \mathrm{C}$ (vide Anexo II). El color de las pastas oscila desde el beige, naranja, salmón, rosáceo hasta el rojizo. El mismo color ofrecen las superficies, algunas de las cuales tienen engobe, generalmente del mismo color que la pasta, en la superficie exterior; en otros casos tienen un pulido que da a las superficies un aspecto suave y brillante. Las cerámicas grises también tienen una buena factura, la cocción es reductora y las superficies se presentan con engobe o pulidas.

\section{LAS FORMAS (figs. 4-7)}

Se conservan preferentemente galbos, en menor medida bordes, y, excepcionalmente, algunas bases. El estado de fragmentación que presentan -no hay ningún recipiente entero- dificulta la reconstrucción de sus formas. Aun así, hemos identificado entre siete y ocho tipos (un tipo con dudas puede ser jarro o botella) correspondientes a los Grupos funcionales I, II y III de la clasificación de Mata y Bonet (1992: 120). El Grupo I, incluye los recipientes de mayor tamaño, empleados para almacenaje o transporte; el Grupo II engloba vasijas de diferente morfología y funcionalidad, relacionadas con la despensa o las actividades domésticas y artesanales; por último, el Grupo III está constituido por aquellos recipientes destinados al servicio o vajilla de mesa.

\section{RECIPIENTES DE ALMACENAJE Y DESPENSA}

A I.2. Tinaja; A I.5. Orza; A II.2. Tinajilla; A II.10. Tarro

Se han documentado sobre todo recipientes de gran tamaño utilizados generalmente para el almacenamiento o el transporte de líquidos o sólidos, entre los que destacan numéricamente las tinajas o tipo A I.2. (Mata y Bonet 1992: 127) (fig. 4, 3, 5 y 6), una de ellas en cerámica gris (fig. 4,7). La cerámica tosca o de cocina de Alarcos no se caracteriza por presentar este tipo de decoración, únicamente se conoce un ejemplar, pues su finalidad práctica no la hace la más adecuada para contener un tipo de decoración cuidada y especial, no obstante, sí aparece en otras áreas peninsulares, lo que resulta llamativo precisamente por su excepcionalidad tal y como ocurre en la comarca Requena-Utiel (Valor et al. 2005: 113).

Los recipientes en los que con mayor frecuencia aparecen motivos impresos son los de tamaño medio. En concreto las tinajillas o forma A II.2. de Mata y Bonet (1992:127), es la forma más representada (fig. 5, 1-3, 5), con impresiones generalmente bajo el borde y cuerpo de forma globular. Tendrían diferentes funciones, destacando 


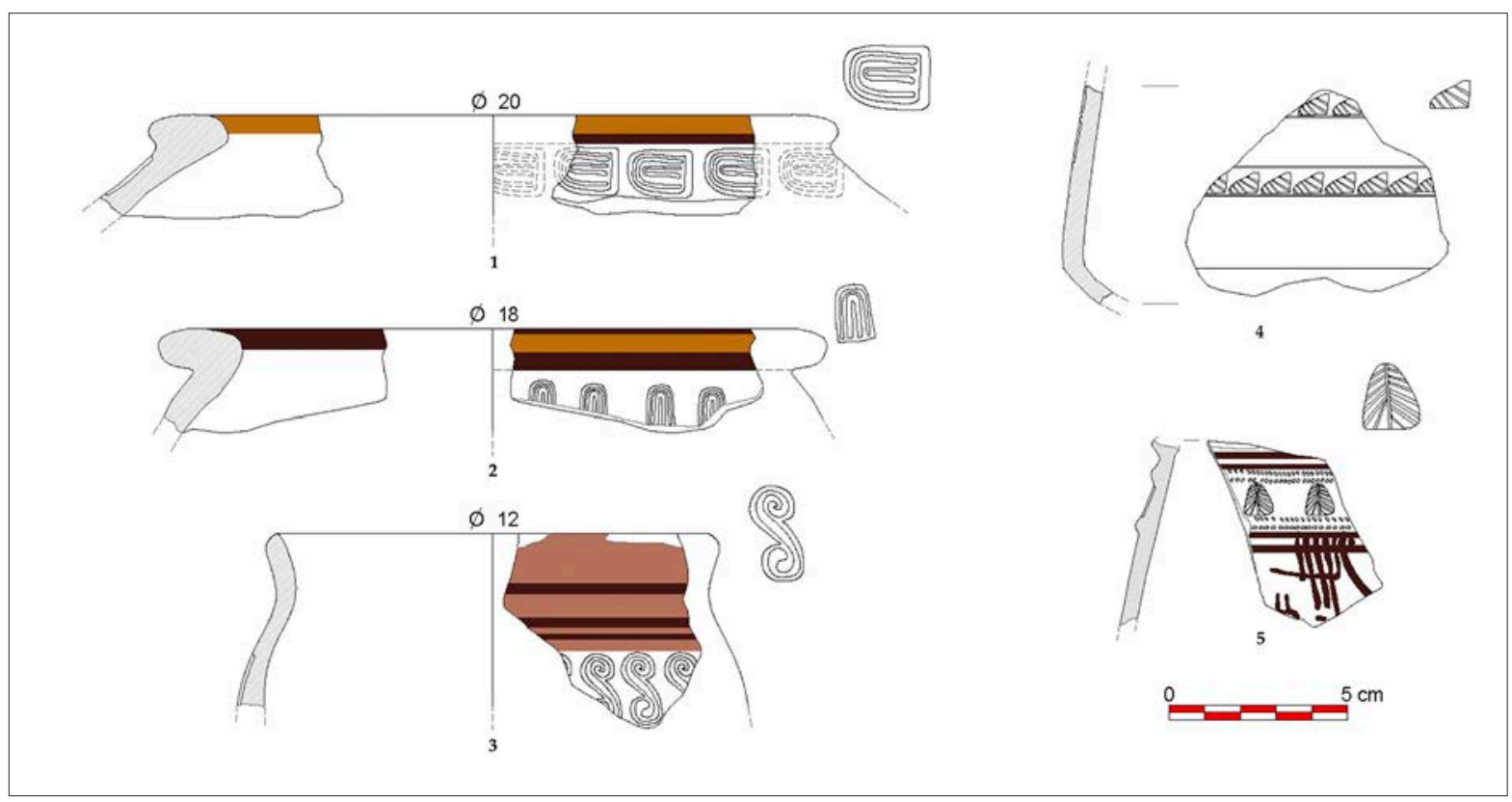

Fig. 5: Recipientes de almacenaje y despensa: 1-3: Tinajillas; 4: Tarro; 5: Tinaja o tinajilla.

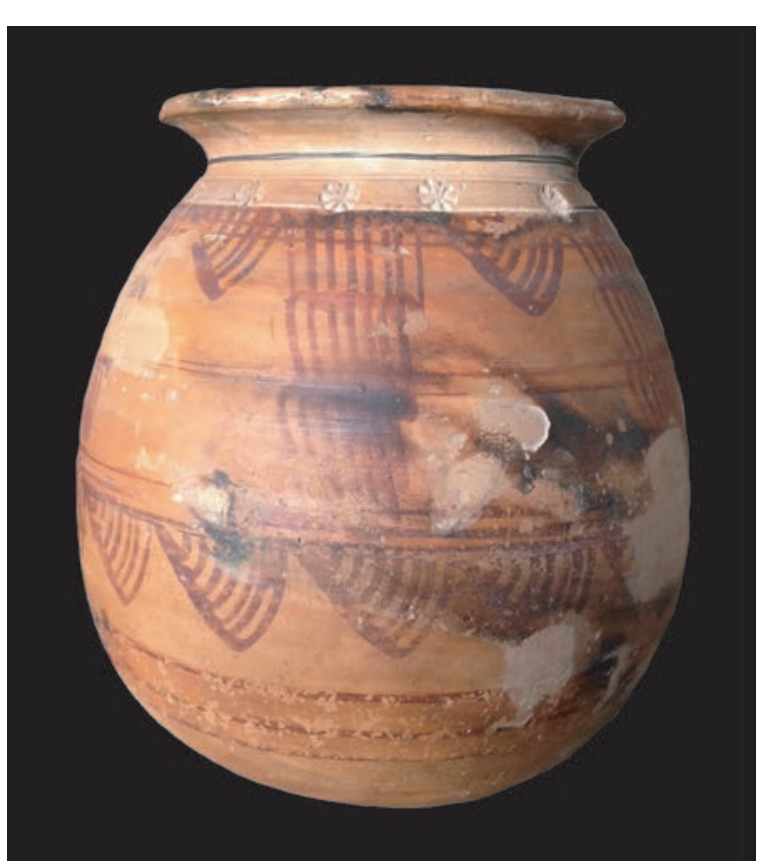

Fig. 6: Tinaja de Alarcos procedente de un hallazgo casual.

su utilización en tareas domésticas de despensa, para guardar líquidos o granos, o para la preparación de alimentos, pero sin exponer directamente al fuego. Estos recipientes probablemente estarían situados en vasares o alacenas y es posible que se usaran en actos rituales, de hecho, aparecen bien representados en áreas de santuarios y como urnas destinadas a recoger los restos cremados de difuntos en las necrópolis. Respecto al primer caso podríamos mencionar como ejemplo las cerámicas aparecidas en el Cerro de los Santos (Hornero del Castillo 1990: 181-183). En lo relativo a las necrópolis igualmente típicos los ejemplos del vaso de los dragones de la necrópolis de la Hoya de Santa Ana (Chinchilla). Las estampillas presentan como motivo decorativo tres hipocampos, teniendo uno de ellos un pequeño pez debajo (Blech y Blech 2002-2003: 246) o bien, ya en la provincia de Cuenca, las estampillas halladas en las Madrigueras o en la de Virgen de la Cuesta de Alconchel, que presenta en su base tres estampillas con motivos zoomorfos (Rodríguez 2012: 799).

Dentro del Grupo II se han registrado tres tarros (fig. 4, 4; fig. 5, 4), uno de ellos en cerámica gris.

Los kalathoi y caliciformes decorados con motivos impresos hallados en otras áreas del yacimiento de Alarcos (Morales 1993) no han sido, hasta el momento, identificados en el Sector III.

Resulta curiosa la total ausencia de recipientes completos con este motivo decorativo en nuestras excavaciones y, sin embargo, en hallazgos "casuales" de los años sesenta del siglo pasado, se localizó una tinaja entera, hecha a torno, con cocción oxidante de pastas y superficies 


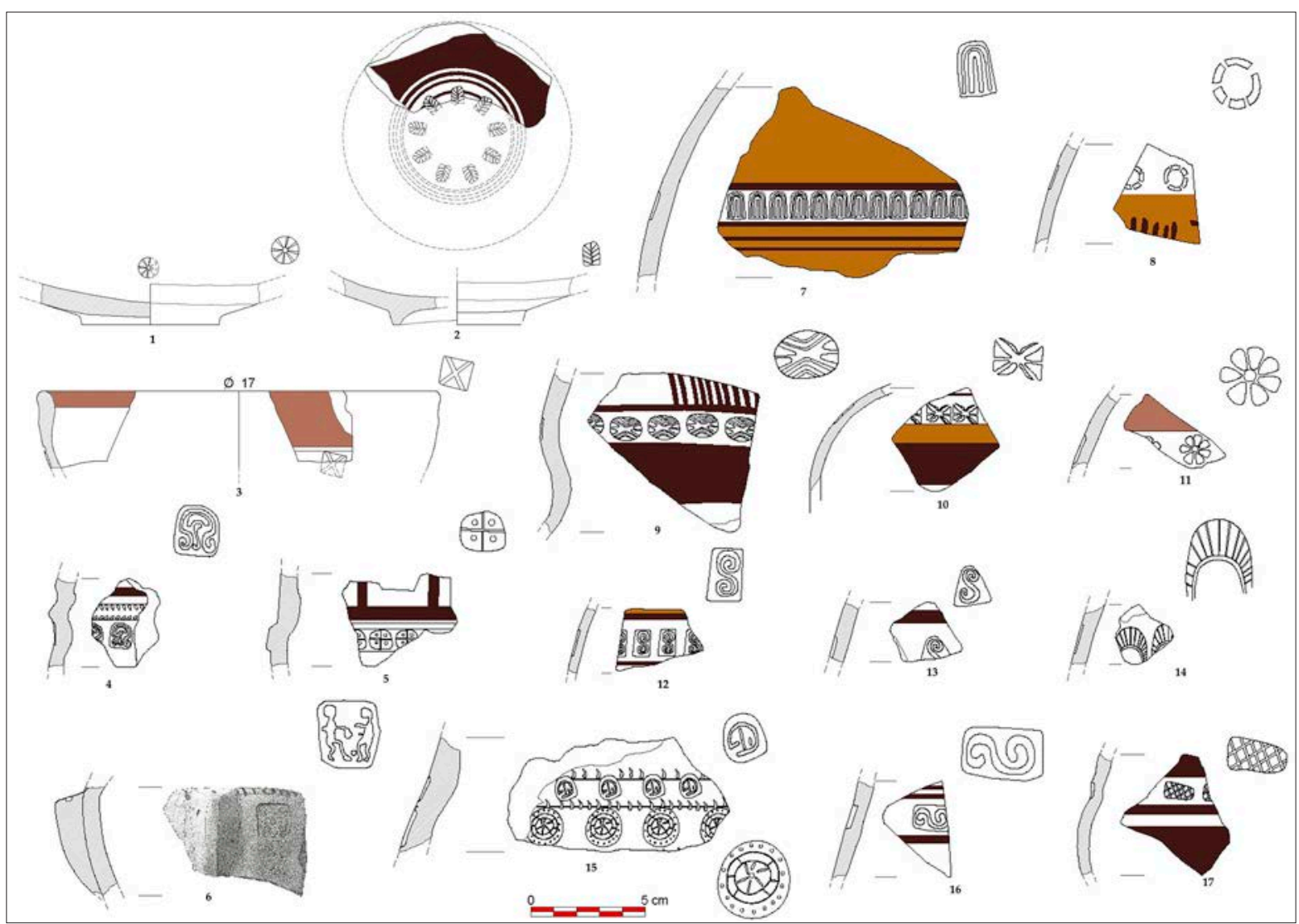

Fig. 7: Recipientes relacionados con el servicio de mesa: 1 y 2: Platos; 3: Cuenco; 4 y5: Jarros o botellas. Otros: 6: Estampilla; 7-17: Informes.

anaranjadas, desgrasante fino y la superficie exterior con engobe. El cuerpo es globular y tiene un cuello corto acabado en un borde vuelto. La base es cóncava. Presenta una rica decoración pintada, monocroma de color rojo que se extiende por todo el recipiente desde el cuello a la base, con motivos decorativos de líneas y bandas paralelas, segmentos de círculos concéntricos y bucles o cabelleras. Bajo el borde lleva una línea de soles impresos, la decoración más habitual (fig. 6).

\section{SERVICIO DE MESA}

Las formas relacionadas con el servicio de mesa corresponden al Grupo III de Mata y Bonet (1992: 131134). Hemos documentado los tipos A III.1 .: Botella o A III.2.: Jarro (fig. 7, 4-5); A III.8.: Plato (fig. 7, 1-2) y A III.9.: Cuenco (fig.7, 3). Es bastante habitual encontrar motivos impresos en formas cerámicas elaboradas para ser empleadas en actividades más delicadas como servir alimentos (platos), libación y dispensación de líquidos (jarros y botellas) y para beber (cuencos y caliciformes).
Al tratarse de un motivo decorativo especial, parece lógico que su fabricación estuviese pensada para un tipo de finalidad en la que la ornamentación tuviese un papel más destacado.

Una de las formas identificadas con la vajilla de mesa es el jarro. Hasta la fecha se conoce con seguridad un jarro de cerámica gris, del que se conserva un fragmento perteneciente al cuello. Tiene las pastas y las superficies grises y está decorado con dos filas de estampillas y un triángulo inciso (AL-03-U12-3). A esta forma podrían corresponder dos fragmentos más, si bien el tamaño de los restos nos hace dudar de su adscripción al tipo jarro o botella, aunque en uno u otro caso el uso sería similar.

Los platos identificados son cuatro, tienen pastas de gran calidad y las superficies de color beige anaranjado. Solo conservan la base, con pie anillado, están decorados en el interior, uno de los fragmentos con círculos pintados de color marrón y un círculo de estampillas (fig. 7, 2), que parece evocar modelos itálicos, y el resto solo con estampillas (fig. 7, 1). 
Por último, la pieza (fig. 7,3) encontrada en un nivel superficial, nos plantea la duda de si se trata de un cuenco, en cuyo caso sería el único conservado, o un plato. Tiene el borde ligeramente exvasado y está decorado en la superficie exterior con una banda pintada muy ancha, de color marrón, junto con una estampilla, que no se conserva completa. El borde interior está decorado con una banda pintada más estrecha de color marrón.

\section{LAS DECORACIONES}

Los estudios relativos a las cerámicas ibéricas con decoración impresa no han sido abundantes, sobre todo si nos referimos a trabajos cuyo objetivo sea analizar sus características generales o su ordenación tipológica y también a trabajos de conjunto o de ámbito territorial amplio. Dentro de este último tipo destacan las ya clásicas investigaciones de Cura (1971 y 1975), Lillo (1977-78) y de Ruiz y Nocete (1981). Los realizados por Cura (1971 y 1975) se restringen a Cataluña, pero tienen el valor de marcar unas bases de partida para el estudio del tipo de decoración que nos ocupa, estableciendo, además, la diferencia entre impresiones a sello, estampilla propiamente dicha o impresiones simples, es decir, las que estuvieron

\begin{tabular}{|l|}
\hline \multicolumn{1}{|c|}{ Criterio 1. Tipos de enmarques: } \\
\hline A. Enmarques cuadrados. Formas cuadradas y rectangulares. \\
\hline B. Enmarques circulares. Formas circulares y las ovaladas. \\
\hline $\begin{array}{l}\text { C. Enmarques triangulares. Formas triangulares claras, } \\
\text { semicírculos, cordiformes y ojivales. }\end{array}$ \\
\hline D. Enmarques de forma adaptada al motivo. \\
\hline \\
\hline I. Motivo en eje. \\
\hline II. Motivo radial. \\
\hline III. Motivo reticulado \\
\hline IV. Motivo concéntrico. \\
\hline V. Motivo en líneas curvas no cerradas. \\
\hline VI. Motivos en líneas quebradas no cerradas. \\
\hline VII. Motivos no representativos. \\
\hline VIII. Motivos figurativos. \\
\hline
\end{tabular}

Fig. 8: Criterios de clasificación de los motivos impresos según Ruiz y Nocete (1981: 356-357). realizadas con un cilindro o una cuerdecilla metálica y, además, son en buena medida la base de otra ordenación más amplia territorialmente (Lillo 1977-1978). Este autor, aunque de manera sucinta, traza por primera vez una panorámica territorial más amplia de este tipo de decoraciones, incidiendo en aspectos como su cronología o su tipología iconográfica. Además, realiza una primera ordenación por clases de estampillas y recoge todos los tipos de motivos que habían ido apareciendo en diferentes partes de la Península, sin restringirse solamente al ámbito íbero. Por su parte, Ruiz y Nocete (1981) organizan y catalogan estas cerámicas a partir de dos criterios. Por un lado, atienden al tipo de enmarque de la estampilla y, por otro, realizan una tipología de motivos basándose en sus formas geométricas, sumando a estas categorías los motivos menos comunes ("no representativos") y los figurativos (antropomorfos o zoomorfos). De esta manera, establecen una catalogación que puede realizarse de manera alfanumérica, que supera las clásicas descripciones de corte iconográfico realizadas hasta la fecha.

En el citado trabajo se analizan cerámicas procedentes del Alto Guadalquivir, pero se realiza un muestreo más amplio estableciendo una comparativa porcentual de los tipos de estampillas que aparecen en distintas zonas como La Mancha, Cataluña o Murcia (Ruiz y Nocete 1981: 382). En nuestro caso, hemos optado por esta ordenación tipológica (fig. 8).

Los sucesivos estudios han tomado como base teórico-metodológica los hasta ahora mencionados y se han centrado en el estudio de colecciones de estampillas procedentes de diferentes territorios. Por su cercanía o por pertenecer directamente a nuestro ámbito de estudio destacamos las aportaciones de Mata (1985), Valor et al. (2005) o más recientemente Fumadó (2014) y en lo que a la Oretania septentrional se refiere son particularmente interesantes las interpretaciones de Esteban (2000) o Fernández et al. (2007) sobre la abundante colección de estampillas halladas en el cerro de las Cabezas (Valdepeñas, Ciudad Real) y la posibilidad de que fuera un gran centro de producción de este tipo de cerámicas. A partir de los motivos impresos y estampillados documentados en el cerro de las Cabezas resulta indudable que, tanto la fabricación de las matrices como su uso sobre piezas cerámicas, constituyó una de las señas de identidad de sus alfareros, pues de otro modo no se podría entender la gran variedad de motivos existentes y su significativa presencia, no sólo en el propio yacimiento sino en otros del ámbito territorial controlado por él. Es tal el desarrollo, 
numérico -casi 3500 cerámicas con este tipo de decoración (Fernández et al. 2007: 216)- variedad y alto grado de creatividad de las cerámicas ibéricas exhumadas que hace décadas incluso se acuñó la denominación de cerámicas "tipo Valdepeñas". Esta nomenclatura ya no se utiliza, pero se justificaba al detectarse que el cerro de las Cabezas sería un centro alfarero de gran magnitud que irradiaría sus cerámicas al menos a toda el área que actualmente conforma la provincia de Ciudad Real, así como a ciertas zonas aledañas, sobre todo a Toledo. Gran parte de esta difusión se ha podido rastrear gracias a la localización de cerámicas con motivos estampillados idénticos, como luego expondremos. Además, en Valdepeñas se han contabilizado más de doscientos tipos diversos de motivos impresos y variantes de los mismos, aspecto que igualmente nos indica la importancia que a esta técnica le otorgaron los artesanos de este lugar. A la par hay que destacar el amplio abanico de motivos figurativos, dato relevante teniendo en cuenta que suelen ser los menos representados. Por poner algunos ejemplos citaremos la famosa cabeza de toro antropomorfizada, también el recurrente uso de la imagen del lobo o sobre todo los guerreros enfrentados, motivo parecido al encontrado en Alarcos, aunque no idéntico, estando todas enmarcadas en el s. IV a. C. (Fernández et al. 2007: 219-220).
Incluso hay otras evidencias de la notoriedad alcanzada por el uso de estos motivos como es el hecho de que todavía en el momento terminal de la ocupación del sitio se seguían utilizando profusamente y que además en yacimientos alejados como el detectado en el paraje de las Esperillas, Madridejos (Toledo) se ha podido comprobar que contaban con cerámicas adquiridas en Valdepeñas. Una de las tinajillas registradas tiene el mismo motivo figurativo, el lobo, y es imagen idéntica en todos y cada uno de sus aspectos a la documentada en la vasija localizada en el cerro de las Cabezas (Rodríguez y Palencia 2014: 13-15).

No obstante, en lo que a Alarcos atañe, inferimos que no podemos establecer una vinculación tan directa entre estos dos grandes enclaves puesto que no tenemos elementos que nos indiquen que en las cercanías de Ciudad Real se dieran las especificidades que observamos en el cerro de las Cabezas, empezando porque ni se han descubierto centenares de motivos diferentes, las figurativas son extremadamente excepcionales y además tampoco podemos establecer, en principio, que Alarcos tuviera una capacidad de difusión de sus producciones a ámbitos tan alejados, como luego explicaremos.

Volviendo a nuestro objeto principal de estudio, en toda la bibliografía reseñada se establecen unas ideas generales que consideran que la decoración impresa aparece

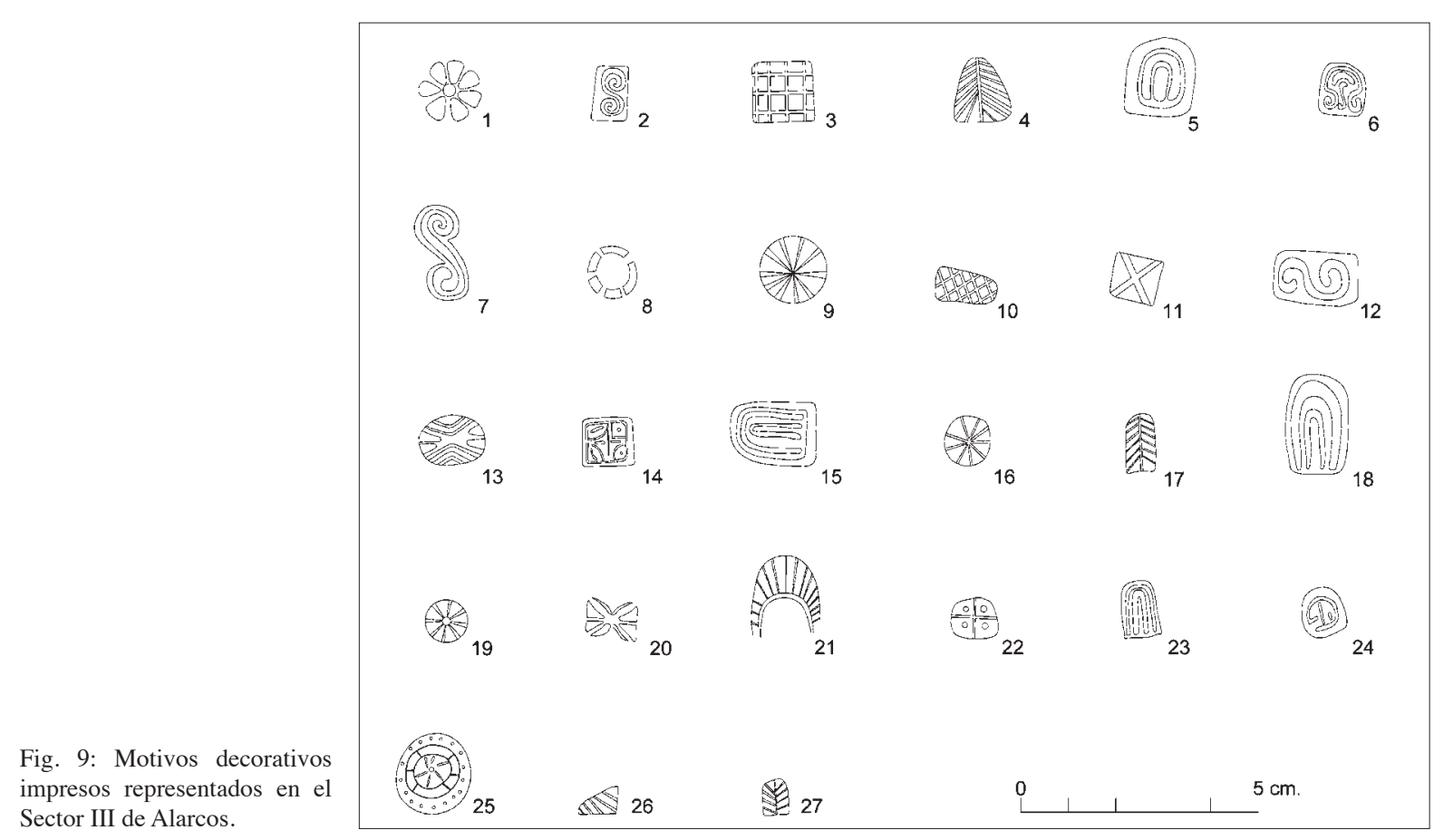




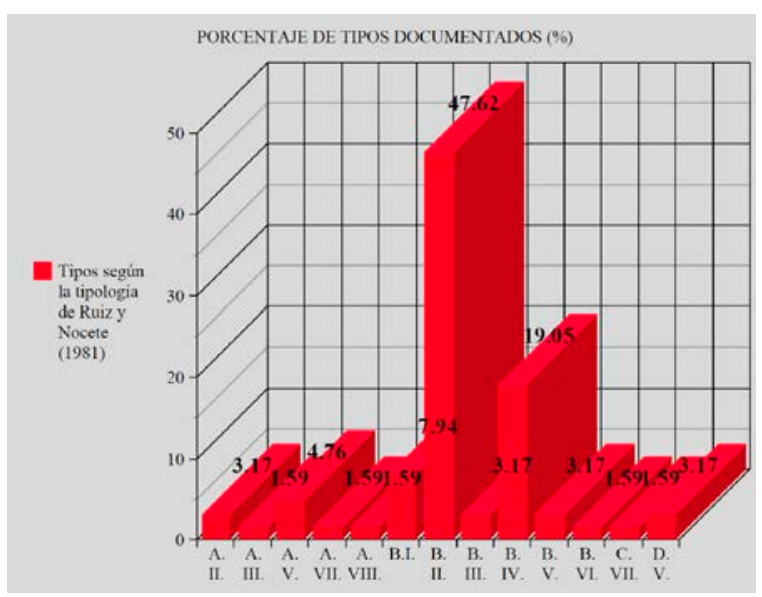

Fig. 10: Gráfico de porcentajes de tipos de motivos en el Sector III de Alarcos.

básicamente en los pueblos del interior del territorio íbero. Para Mata (1985: 177-178) su aparición y desarrollo se sitúa entre los ss. V y II a. C., aunque algunos autores elevan la cronología para el origen de esta decoración al s. VI a. C. o inicio del V a. C. (Fumadó 2014: 91) a tenor del reciente estudio realizado sobre una estampilla figurativa de El Macalón (Nerpio, Albacete) que ya había sido catalogada por Mata y Soria (1997: 320). A pesar de ello, el auge de estas decoraciones en los territorios interiores se produjo a partir del s. IV a.C. y sobre todo desde el III a. C., según se desprende de las cronologías que aportan yacimientos como el cerro de las Cabezas (Fernández et al. 2007: 211-227) y territorios como Andalucía (Ruiz y Nocete 1981) o Kelin (Valor et al. 2005).

Para el análisis y clasificación de las cerámicas ibéricas con ornamentación impresa de Alarcos hemos utilizado la tipología de Ruiz y Nocete (1981) cuyo rigor descriptivo ayuda a recoger y comparar con claridad los tipos. Sobre 58 fragmentos cerámicos había 63 motivos y 27 tipos distintos de diseños (figs. 9 y 10).

La variabilidad en los tipos de motivos documentados, según los criterios ya aludidos de forma del enmarque y de tipo de motivo, pone de manifiesto que contamos con los cuatro tipos de enmarques conocidos, A, B, C y D. A pesar de ello, los tipos C (triangulares) y D (adaptado al motivo), son casi anecdóticos, con uno y dos ejemplares $(1,59 \%$ y $3,17 \%)$ respectivamente (fig. 11$)$.

En consecuencia, los tipos de enmarque relevantes son el A (cuadrados-rectangulares) y sobre todo el B (circulares-ovalados). Los enmarques cuadrados (tipo B) presentan una abrumadora mayoría, alcanzando el
$82,15 \%$ del total de las estampillas del Sector III de Alarcos. Por su parte el tipo A supone el 12,65\%. Si comparamos estos datos con los de otros territorios podemos conocer mejor las características de los motivos estampillados de nuestro ámbito: en el estudio de Ruiz y Nocete (1981: 382), se incluye una estadística acerca de los porcentajes de los tipos en diversas zonas como el Alto Guadalquivir, Cataluña, La Mancha y Murcia. Así, el enmarque tipo B es el predominante en Cataluña $(52,63 \%)$ y Murcia $(77,77 \%)$. Por el contrario, en el Alto Guadalquivir predomina el tipo A (61,94\% frente al 28,31 del tipo B). Sorprendentemente este estudio especifica que en La Mancha el enmarque tipo $C$ es el más numeroso $(48,38 \%)$, seguido del B con el $32,25 \%$. Bien podría parecer que las estampillas del Sector III de Alarcos contradicen la norma establecida, pero realmente no es así. Hay que tener en cuenta que los datos especificados pertenecen a inicios de los años ochenta y, por tanto, dos de los grandes oppida de la Oretania septentrional todavía no estaban siendo excavados. Con los datos del cerro de las Cabezas, a partir de 1985, y del Sector III de Alarcos, cuyos trabajos de excavación se iniciaron en 1997, podemos argumentar que los tipos A y B son los mayoritarios en este territorio, al contrario de lo que mostraban los estudios reseñados de los años ochenta con la preponderancia del C, obteniendo así valores similares a los del resto del territorio íbero. Este aspecto es un hecho constatable tanto para Alarcos como para el cerro de las Cabezas, a pesar de no disponer de este último lugar de una estadística completa por tipos (Fernández et al. 2007: 216).

El siguiente criterio afecta al propio motivo. Se ordena por formas geométricas y alguna otra categoría como las líneas y su trayectoria o los motivos figurativos en sí. El número de tipos registrados es alto si tenemos en cuenta lo reducido de la muestra. Hemos catalogado hasta 13 tipos diferentes (fig. 11), aunque de cinco de ellos (A.III; A.VII; A.VIII; B.VI y C.VII) tan solo contamos con un ejemplar. Los tipos dominantes son el B.II (30 piezas, 47,62\%) y B.IV (12 fragmentos, 19,05\%). De esta forma, el $66,67 \%$ son piezas de enmarque circularovalado y de motivo circular (B.II) o concéntrico (B.IV). Estos datos van en consonancia con los observados en el estudio de Ruiz y Nocete (1981: 382), en el cual también son tipos importantes, constatándose que los tipos B.II y B.IV siempre están en cada caso en torno al $20 \%$ de los registros, a pesar de lo reducido y antiguo de la muestra que consigna ese trabajo. Por el contrario, en el territorio de Kelin (Valor et al. 2005: 116) vemos notables diferencias 
Fig. 11: Motivos decorativos impresos representados en el Sector III de Alarcos, según la tipología de Ruiz y Nocete (1983).

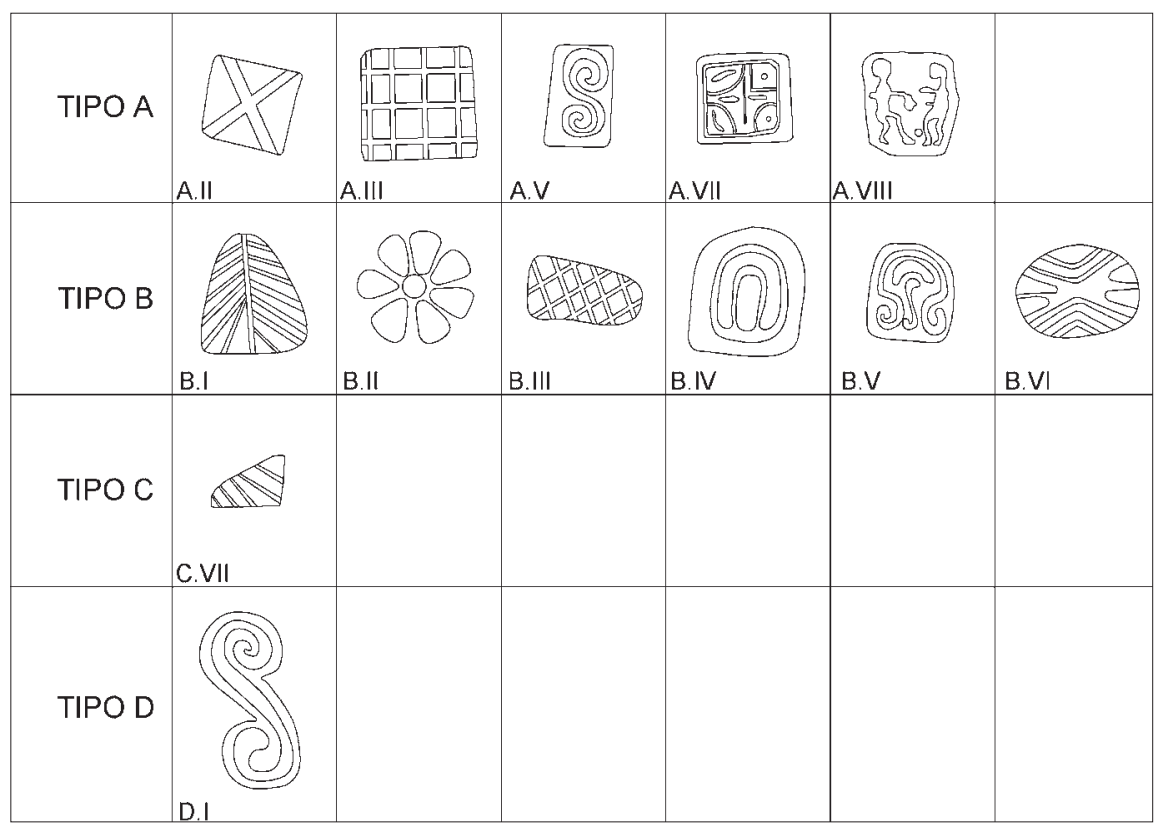

puesto que los tipos mayoritarios son el B.V (14\%), D.V (6\%), B.II $(4,5 \%)$, seguidos del B.I y D.IV (3\% cada uno). Estos porcentajes describen un panorama distinto en el que los enmarques circulares y motivos radiales o concéntricos aglutinan el grueso de la muestra.

Muchos de los motivos de Alarcos presentan imágenes idénticas a las documentadas en otras zonas. Es el caso de las ovas y algunos motivos vegetales, las eses o serpentiformes, los motivos solares-radiales o los cuadrados cruzados por líneas. Lo mismo ocurre en el caso de los motivos florales o rosetas, que pueden ser crucíferas, monocotiledóneas y dicotiledóneas en función del número de pétalos (Mata et al. 2010: 109-113). En Alarcos aparecen del último tipo, con siete y ocho pétalos. Este motivo se ha hallado en otros muchos lugares como por ejemplo el Alto Guadalquivir (Ruiz y Nocete 1981: 361, fig. 4, motivo 5), en el SE (Lillo 1977-1978: fig. 5, motivo 16) o también en zonas mucho más cercanas a Alarcos como Villanueva de la Fuente, y en La Bienvenida (Almodóvar del Campo) (Rodríguez 2012: 827-828). Los cuadrados cruzados por aspas o líneas son muy comunes en toda Andalucía (Ruiz y Nocete 1981: 358-359, figs. 1 y 2 , motivos 5 y $6 ; 1,2,3,4,5,6,7,8)$. Las ovas y otros motivos vegetales también son elementos muy representados en todas las áreas, incluso en ámbitos diferentes al mundo íbero como Galicia o en otros de esta cultura como Cataluña, Valencia, Murcia o el SE andaluz (Lillo 1977-1978: figs. 2, 3, 5, 6). Con las eses o serpentiformes sucede algo similar, son frecuentes en diversas partes de la Meseta, en la Alta Andalucía (Ruiz y Nocete 1981: fig. 2, 3 y 4, motivos 17, 20; 13, 14, 15; 26 y 27), siendo también abundantes en el Cerro de San Cristóbal (Valor et al. 2005: 108, fig. 2, 8 y 10; fig. 4, 10). El resto de motivos, aunque menos representados, tienen igualmente semejanzas con otros muchos de diversas localizaciones. Llama la atención que el identificado en nuestro $n^{\circ} 20$ (fig. 9) sea muy similar a los hallados en Galicia (Lillo 1977-1978: fig. 2,19), ocurriendo lo mismo con otros muy recurrentes en la zona de Cástulo o el SE andaluz que son iguales que nuestros ejemplos $\mathrm{n}^{\text {os }} 4,5,8,15,18$, etc. (fig. 9).

En definitiva, los motivos mayoritarios de AlarcosSector III son comunes y aparecen tal cual o con ligeras variantes, que no afectan a su iconografía, en otras zonas geográficas. Por lo tanto, parece que los alfareros de Alarcos a la hora de decidir qué tipo de motivo estampillado iban a emplear en sus producciones cerámicas pudieron seguir, en gran medida, los gustos y tendencias que de forma generalizada se empleaban en gran parte del territorio ibérico. No obstante, también resulta lógico pensar que, en cada territorio, incluso en cada centro productor de cerámica, hubiese cierto margen para la creatividad y la definición de motivos propios o menos comunes. En este sentido, podemos mencionar el caso de algunos motivos de Alarcos (fig. 9, 14, 24 y 25) de los que no hemos localizado paralelos en otros lugares. 
Un caso singular es la única estampilla figurativa del Sector III (fig. 7, 6 y fig. 12), perteneciente al tipo A.VIII. Dentro de un enmarque cuadrangular aparecen dos individuos masculinos enfrentados, realizando algún tipo de actividad y entre ellos hay dos círculos o bolitas. Solamente hemos encontrado una similar en el Cerro de las Cabezas, interpretada como dos guerreros o personas que se disponen a luchar o a danzar (Fernández Maroto et al. 2007: 220 y 222, fig. 10). En el ejemplar que presentamos no se visualiza con claridad lo que están haciendo las dos figuras, aunque podemos descartar que la escena sea la misma, pues en la estampilla de Valdepeñas se observan dos escudos cuadrados y en la de Alarcos este objeto no existe. La técnica de trazo de las figuras humanas, sus proporciones e, incluso, la manera en la que aparecen cara a cara nos invita a pensar que pueden tener alguna vinculación, al menos formal y estética e, incluso, simbólica. Las dimensiones de la estampilla $(1,5 \mathrm{~cm} \times 1,2 \mathrm{~cm})$ sugieren que el objeto empleado como tampón para su impresión fuera una plaquita, quizás de un metal noble.

En la zona de la Alcazaba se documentaron dos sellos que destacan por su cuidadosa elaboración. Uno representa la cabeza de un animal, probablemente un felino, vista de perfil y otro reproduce a un cánido en movimiento (Morales 1993: 196). Estas piezas revelan el alto grado

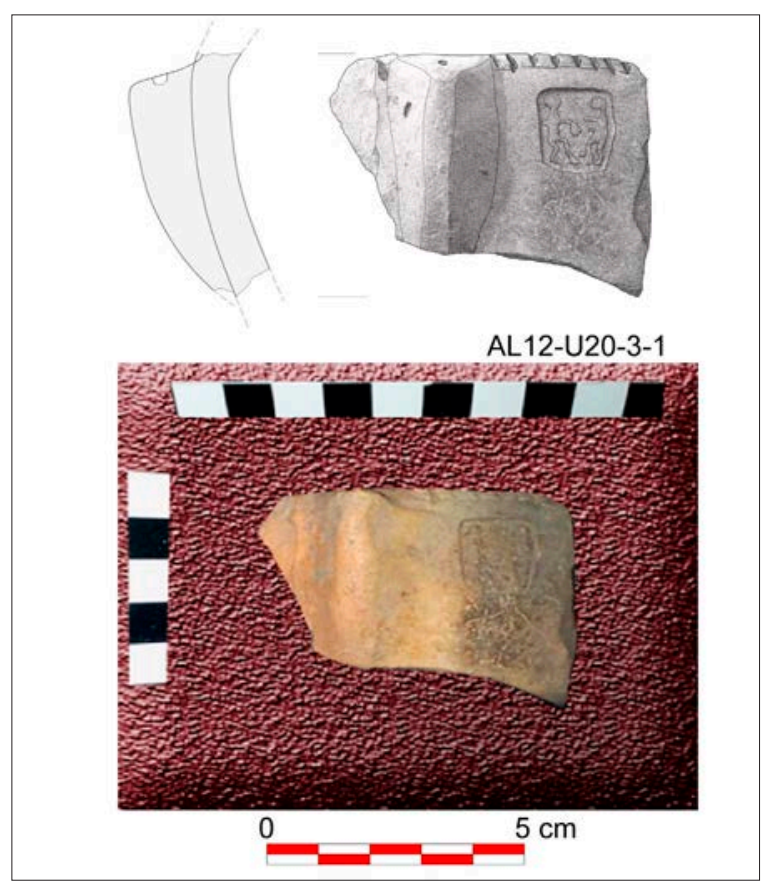

Fig. 12: Estampilla con motivos figurativos del Sector III de Alarcos. de perfección técnica alcanzado por los artesanos de Alarcos y, además, contienen una lectura de carácter simbólico. En el primer caso se trata de un animal exótico del imaginario de los iberos, lo que no excluyó su representación en distintos soportes como piedra, cerámica o metal vinculados fundamentalmente a contextos funerarios, y el segundo, presente en la iconografía ibérica desde el s. V a.C., con un significado eminentemente emblemático y aristocrático y reproducido igualmente en los soportes mencionados (Mata 2014: 130-135).

En definitiva, si valoramos en su conjunto los datos de este apartado, observamos que las cerámicas de Alarcos tienen analogías, sobre todo, con las cerámicas del Alto Guadalquivir y también con las de las áreas de Valencia. Resulta tentador relacionar este hecho con los evidentes vínculos culturales que existían entre las poblaciones ibéricas del valle del Guadiana y del Alto Guadalquivir, que compartieron intereses comunes en diversos aspectos como la economía y la religiosidad, lo cual, muy probablemente, también tendría cierta plasmación en la asunción de tradiciones comunes en otros ámbitos como la producción cerámica y los gustos estéticos. Estas afirmaciones se sustentan en que las características tecno-tipológicas de las cerámicas del Alto Guadalquivir, por ejemplo, respecto a las de Alarcos no difieren en exceso. Gracias a estudios generales y ya clásicos (Pereira 1988: 143-173; 1989: 149159) observamos que las alfarerías propias del sur de Sierra Morena respecto a las del norte, en lo que se refiere a formas, variedades, calidad o tipos de decoración, incluyendo por supuesto los motivos impresos, son asimilables.

\section{POSICIÓN DE LOS MOTIVOS IMPRESOS EN LA CERÁMICA}

A pesar de que la disposición de las decoraciones impresas en los recipientes ibéricos no sigue un canon determinado, sí parece responder a una serie de normas básicas. Lo más habitual es que esta decoración se localice en el tercio superior de los vasos, es decir, en el área de los bordes o en la zona de transición entre la pared y el cuello, característica que es común a todos los territorios en las que se documenta este tipo decorativo, lo cual refuerza la idea de que era una ornamentación diseñada para ser contemplada con facilidad, preferentemente de manera frontal. Es frecuente que la parte de la pared en la que se dispone el motivo impreso se refuerce con un ligero engrosamiento o bien que aprovechen las zonas de mayor grosor como, por ejemplo, el arranque del cuello y 
los bordes. Los motivos impresos eran empleadas por los artesanos ibéricos como elementos decorativos selectos, por ello no debían ser ubicadas en lugares del recipiente en las que pudieran pasar desapercibidos, de hecho, comprobamos en Alarcos que para facilitar la percepción de los motivos impresos éstos suelen aparecer enmarcados o delimitados por diferentes elementos, como impresiones simples, incisiones o motivos pintados, preferentemente líneas y bandas. Cuando se trata de platos o formas abiertas la decoración se sitúa en la cara interna de la base.

\section{COMBINACIONES Y ASOCIACIÓN CON OTRAS DECORACIONES}

Es muy habitual que la ornamentación impresa aparezca junto a otro tipo de decoraciones, siendo común que estén profusamente pintadas. Se asocian a otros elementos decorativos en un $48 \%$ del total. Podemos concluir que era algo común y, además, indicativo de que el motivo estampillado se utilizaba en cerámicas de alta calidad. Dentro de estas asociaciones hemos documentado hasta seis variantes de combinaciones de recursos decorativos. Los fragmentos estudiados suelen asociarse a pintura, incisiones, impresión a ruedecilla y cordones impresos. La asociación más común es la motivo impreso-pintura bícroma de líneas horizontales (marrones o rojas normalmente), seguido de motivo impreso-cordones impresos. El resto de las vinculaciones es minoritario, especialmente la decoración pintada bícroma con ondas y/o segmentos de círculo. Remitimos a la fig. 13, en la que se aprecian las diferentes combinaciones, observándose que la más usual es la combinación líneas pintadas horizontales con motivos impresos, seguidas de la asociación líneas pintadas horizontales junto a un cordón impreso.

En definitiva, como refleja el cuadro de la figura 13, la mayoría de las cerámicas decoradas con motivos impresos también suelen presentar otro tipo de decoración, $82,75 \%$, teniendo solamente como único tipo de decoración la impresión el 17,25\% de los fragmentos.

Otra particularidad de estas producciones en Alarcos es la presencia de talco en su composición. Se han realizado análisis químicos sobre cinco muestras procedentes del Sector III (vide Anexo II) y todas revelan una composición química y mineralógica muy similar a otro grupo de cerámicas ibéricas, sin este tipo de ornamentación, estudiadas en este mismo sector, y también caracterizadas por la existencia de talco.

\begin{tabular}{|l|c|c|}
\hline \multicolumn{3}{|c|}{$\begin{array}{c}\text { Relación de otros motivos decorativos con las cerámicas } \\
\text { estampilladas }\end{array}$} \\
\hline Asociación & $N^{\text {o }}$ de casos & Porcentaje \\
\hline $\begin{array}{l}\text { Decoración pintada (Líneas } \\
\text { horizontales) }\end{array}$ & 32 & $66,68 \%$ \\
\hline $\begin{array}{l}\text { Decoración pintada (Líneas } \\
\text { verticales) }\end{array}$ & 1 & $2,08 \%$ \\
\hline $\begin{array}{l}\text { Decoración pintada (Líneas } \\
\text { horizontales y segmentos) }\end{array}$ & 3 & $6,25 \%$ \\
\hline $\begin{array}{l}\text { Decoración pintada (Líneas } \\
\text { horizontales) y cordón impreso }\end{array}$ & 6 & $12,50 \%$ \\
\hline $\begin{array}{l}\text { Decoración pintada (Líneas } \\
\text { horizontales y ondas) y cordón } \\
\text { impreso }\end{array}$ & 1 & $2,08 \%$ \\
\hline Cordón Impreso & 4 & $8,33 \%$ \\
\hline Ruedecilla & 1 & $2,08 \%$ \\
\hline Total & $\mathbf{4 8}$ & $\mathbf{1 0 0} \%$ \\
\hline
\end{tabular}

Fig. 13: Relación de otros motivos decorativos con las cerámicas impresas.

Las características señaladas y, sobre todo, los resultados de las analíticas nos llevan a plantear que estas cerámicas corresponderían a una producción propia de Alarcos. Desde aquí se llevaría a cabo su comercialización y/o redistribución a los poblados del entorno. Se han documentado fragmentos de cerámica estampillada con motivos idénticos a los registrados en el sector III, en el yacimiento de Valdarachas, a poco más de $6 \mathrm{~km}$ al sur de Alarcos (Morales 1993: 121). También se han detectado en los poblados de Celada, Las Casillas, Arroyo de las Ánimas I y II, Sancho Rey o Santa María de la Puebla, todos ubicados en un radio de $6-8 \mathrm{~km}$ respecto a Alarcos (Rodríguez et al. 2016: 92-93). No descartamos que también fuera un centro receptor de las producciones impresas del cerro de las Cabezas, si bien, las halladas hasta el momento no parecen indicarlo.

\section{CONCLUSIONES}

Los artesanos de Alarcos dedicaron una parte de su producción a elaborar recipientes con ornamentación impresa, que en un elevado porcentaje responde a una cierta estandarización de motivos, pero también dejaron un espacio reservado a la realización de estampillas con motivos complejos o figurativos, portadoras de un significado reconocible por la comunidad o ciertos grupos sociales. El porcentaje de cerámicas ibéricas de Alarcos con motivos 
impresos en los diversos sectores o zonas de excavación no supera el $4 \%$ del total, algo habitual en los yacimientos y zonas peninsulares donde se documentan estas producciones. A pesar de lo reducido de la muestra, se han diferenciado 27 tipos de diseños distintos, agrupados en 13 tipos de motivos. El enmarque dominante es el tipo B o enmarque circular u oval, con motivo radial (B.II) y motivo concéntrico (B.IV), que suponen más del $66 \%$ de los diseños identificados. El siguiente es el tipo A o enmarque cuadrado-rectangular, que aparece en el 12,65\% de las piezas.

La decoración se localiza preferentemente en el tercio superior de las piezas, en la parte alta del cuerpo o bajo el borde. La mayoría de los fragmentos (75\%), combinan la ornamentación impresa y la pintada monocroma y, sobre todo, bícroma. Aquellos que integran decoración impresa e impresión a ruedecilla o cordones impresos, aunque representados, se documentan en menor proporción $(10,41 \%)$. Estos aspectos sugieren una producción propia y característica de Alarcos y de su territorio.

Los recipientes documentados son, sobre todo, de mediano (tinajilla, orza y tarro) y pequeño tamaño estando muy representa la cerámica de mesa (botella, jarro, plato y cuenco), tal y como ocurre, en el área de Kelin/ Los Villares (Caudete de las Fuentes) y de Edeta/Tossal de Sant Miquel (Llíria, València) (Valor et al. 2005; Bonet 1995). Las otras dos formas funcionales, de mayor envergadura (orzas grandes y tinajas), se relacionan con el almacenaje de sólidos y líquidos. A nivel de contextos, en el Sector III de Alarcos las producciones estudiadas aparecen de forma mayoritaria en las viviendas ibéricas y en menor medida en el almacén de grano. Aun disponiendo de una muestra poco representativa, se esboza un conjunto de vasijas relacionadas con el almacenaje a pequeña escala y, sobre todo, el servicio de alimentos y bebidas que estaría compuesto por recipientes para la presentación y el consumo (platos), para beber (caliciformes) y para la presentación y la dispensación de líquidos (jarros y/o botellas). Como complemento o apoyo al servicio de mesa estarían las tinajillas, los tarros, las orzas pequeñas.

Tradicionalmente las cerámicas importadas relacionadas con el consumo de vino se han considerado el máximo exponente de ostentación en época plena (Bonet et al. 2004), sin embargo, debieron existir actos no cotidianos que pudieron tener como protagonista a otra producción cerámica local de excelente factura y singular decoración, como la ornamentada con motivos impresos y/o estampillas. Su carácter excepcional las convierte en cerámicas de prestigio (Valor et al. 2005: 123), o, al menos, con un cierto significado especial, que las hace muy adecuadas para su uso y exhibición en momentos especiales.

La composición cualitativa del conjunto de Alarcos, la excelente manufactura de las piezas, su peculiar decoración y la presencia de determinados repertorios (despensa y servicio de mesa) podrían evidenciar su relación con prácticas sociales en situaciones que, eventualmente, pudieron tener un carácter destacado, lo que nos lleva a plantearnos la posibilidad de que nos encontremos ante una producción específica probablemente adscrita a ciertos actos de carácter social. Sin descartar, en función de los contextos de los hallazgos, un uso polifuncional para los recipientes que portan esta decoración-que, además, en el caso de las orzas sería incluso funerario, como se refleja en la necrópolis de Alarcos (García Huerta et al. 2018: 56)-, su presencia mayoritaria en un contexto habitacional evoca la casa como lugar de exhibición del estatus de su dueño y, de ese modo, estas producciones serían empleadas para exhibirlas como objetos de rango y prestigio.

\section{BIBLIOGRAFÍA}

BLECH, M.; BLECH, M. (2002-2003): El Vaso de los Dragones de la necrópolis de Hoya de Santa Ana (Chinchilla, Albacete), Homenaje a la Dra. Dña. Encarnación Ruano. Boletín de la Asociación Española de Amigos de la Arqueología 42, 245-263.

BONET ROSADO, H. (1995): El Tossal de Sant Miquel de Llíria: la antigua Edeta y su territorio, València.

BONET ROSADO, H.; GUÉRIN, P.; MATA PARREÑO, C.; GARIBO, J.; VALOR, J.; VIVES-FERRÁNDIZ, J. (2004): Las ánforas importadas de las comarcas centrales del País Valenciano, Arqueo Mediterrània 8, 203-228.

BUXÓ, R.; PRINCIPAL, J.; ALONSO, N.; BELARTE, M. C.; COLOMINAS, L.; LÓPEZ, D.; PONS, E.; ROVIRA, M. C.; SAÑA, M.; VALENZUELA, S. (2010): Prácticas alimentarias en la Edad del Hierro en Cataluña, De la cuina a la taula. IV Reunió d'Economia en el primer mil·leni a.C. (C. Mata, G. Pérez Jordà, J. Vives, eds.), Sagvntvm-Extra 9, València, 81-98.

CURA MORERA, M. (1971): Acerca de unas cerámicas grises con decoración estampillada en la Cataluña prerromana, Pyrenae 7, 47-60.

CURA MORERA, M. (1975): Nuevos hallazgos de cerámica estampillada gris prerromana en Cataluña, Pyrenae 11, 173-178.

ESTEBAN BORRAJO, G. (2000): Una característica producción cerámica pintada del Período Ibérico pleno en el sur de la Meseta, CUPAUAM 26, 69-84.

DOI:https://doi.org/10.15366/cupauam2000.26.004 
FERNÁNDEZ MAROTO, D.; VÉLEZ, J.; PÉREZ AVILÉS, J. (2007): La cerámica estampillada de tipo figurativo del cerro de las Cabezas (Valdepeñas), Arte Ibérico en la España Mediterránea (Alicante, 2005), 211-227.

FUMADÓ ORTEGA, I. (2014): El caballero de El Macalón (Nerpio, Albacete). La emergencia de las aristocracias ibéricas y sus nuevas formas de representación, CUPAUAM 40, 81-95.

DOI: https://doi.org/10.15366/cupauam2014.40.006

GARCÍA FERNÁNDEZ, F.; GARCÍA VARGAS, E. (2010): Entre gaditanización y romanización: repertorios cerámicos, alimentación e integración cultural en Turdetania (siglos III-I a. C.), De la cuina a la taula.IV Reunió d'Economia en el primer mil·leni a.C. (C. Mata, G. Pérez Jordà, J. Vives, eds.), Sagvntvm Extra 9, 116-135.

GARCÍA HUERTA, R.; MORALES HERVÁS, F. J. (2007): Los oretanos. Prehistoria y Protohistoria de la Meseta Sur (Castilla-La Mancha), Almud, 217-238.

GARCÍA HUERTA, R.; MORALES HERVÁS, F. J. (2009): Almacenamiento, tratamiento y conservación de alimentos en los pueblos ibéricos de la meseta meridional, Sistemas de almacenamiento entre los pueblos prerromanos peninsulares (R. García Huerta, D. Rodríguez, eds.), Cuenca, 167-208.

GARCÍA HUERTA, M. R.; MORALES HERVÁS, F. J.; RODRÍGUEZ GONZÁLEZ, D. (2004): La cerámica griega del oppidum de Alarcos (Ciudad Real), Charisterion. Francisco Martín García Oblatum (I. García, S. Talavera, coord.), Cuenca, 115-130.

GARCÍA HUERTA, M. R.; MORALES HERVÁS, F. J.; RODRÍGUEZ GONZÁLEZ, D. (2018): De la muerte a la eternidad: la necrópolis ibérica de Alarcos (Ciudad Real), Madrid.

GARCÍA HUERTA, R.; MORALES HERVÁS, F. J.; VÉLEZ RIVAS, J.; SORIA COMBADIERA, L.; RODRÍGUEZ GONZÁLEZ, D. (2006): Hornos de pan en la Oretania Septentrional, TP 63 (1), 157-166. DOI: https://doi.org/10.3989/tp.2006.v63.i1.10

GIL FARRÉS, O. (1952): Hallazgo cerámico en Alarcos, II Congreso Nacional de Arqueología, 397-400.

GUIRAO POLO, D. (2014): Caracterización arqueométrica de las cerámicas de época ibérica de Alarcos y del Cerro de las Cabezas (Ciudad Real), Tesis Doctoral Inédita. Universidad de Castilla-La Mancha.

HAYDEN, B. (1996): Feasting in the Prehistoric and traditional societies, Food and the status quest. An interdisciplinary perspective (P. Wiessner, W. Schiefenhövel, eds.), Oxford, 127-147.

HAYDEN, B. (2001): Fabulous feasts: a prolegomenon to the importance of feasting, Feasts archaeological and ethnographic perspectives on food, politics, and power (M. Dietler, B. Hayden, eds.), Washington, London, 23-64.
HORNERO DEL CASTILLO, E. (1990): La cerámica gris en la Península Ibérica. El Cerro de los Santos, un santuario ibérico con cerámica gris, Al- Basit 26, 171- 205.

IBORRA M. P.; MATA PARREÑO, C.; MORENO, A.; QUIXAL, D.; PÉREZ JORDÀ, G.; VIVES-FERRÁNDIZ, J. (2010): Prácticas culinarias y alimentación en asentamientos ibéricos valencianos, De la cuina a la taula. IV Reunió d'Economia en el primer mil·leni a.C. (C. Mata, G. Pérez Jordà, J. Vives, eds.), Sagvntvm-Extra 9: 99-114.

LILLO CARPIO, P. (1977-1978): La cerámica ibérica estampillada, Anales de la Universidad de Murcia, Filosofía y Letras XXXVI, 1 y 2, 11-25.

MARTÍ, M. A. (1994): Cerámicas ibéricas con decoración impresa de Arse (Sagunt, València), Sagvntvm-PLAV 27, 207-211.

MATA PARREÑO, C. (1985): Algunas cerámicas ibéricas con decoración impresa de la provincia de Valencia, SagvntvmPLAV 19, 153-181.

MATA PARREÑO, C. (coord.) (2014): Fauna Ibérica. De lo real a lo imaginario II, Serie Trabajos Varios. S.I.P. 117, València.

MATA PARREÑO, C; BADAL, E.; COLLADO, E.; RIPOLLÈS, P. P. (2010): Flora Ibérica. De lo real a lo imaginario, Trabajos Varios S.I.P. 111, València.

MATA PARREÑO, C.; BONET ROSADO H. (1992): La cerámica ibérica: Ensayo de tipología, Estudios de Arqueología Ibérica y Romana. Homenaje a Enrique Pla Ballester, Serie Trabajos Varios. S.I.P. 89, València, 117-174.

MATA PARREÑO, C.; SORIA COMBADIERA, L. (1997): Marcas y epígrafes sobre contenedores de época ibérica, APL 22, 297-360.

MORALES HERVÁS. F. J. (1993): La cerámica ibérica pintada del poblado de Alarcos, Tesis de Licenciatura Inédita. Universidad de Castilla-La Mancha. Ciudad Real.

MORALES HERVÁS, F. J. (2010): El poblamiento de época ibérica en la provincia de Ciudad Real, Servicio de Publicaciones de la Universidad de Castilla-La Mancha.

NIETO GALLO, G.; SÁNCHEZ MESEGUER, J. (1980): Oreto I. EAE 114.

PEREIRA SIESO, J. (1988): La cerámica ibérica de la cuenca del Guadalquivir (I): propuesta de clasificación, TP 45 (1), 143-173.

DOI: https://doi.org/10.3989/tp.1988.v45.i0.608

PEREIRA SIESO, J. (1989): La cerámica ibérica de la cuenca del Guadalquivir (II): conclusiones, TP 46 (1), 149-159. DOI: https://doi.org/10.3989/tp.1989.v46.i0.592

PINTA, J. L. DE LA (1993): Estampillas sobre producciones cerámicas ibéricas. Una aportación a su catálogo, Gala 2, 143-157.

RODRÍGUEZ GONZÁLEZ, D. (2012): El mundo íbero a través de su cultura material: la cerámica gris de la Oretania septentrional y sus zonas de contacto, Tesis Doctoral inédita. Universidad de Castilla-La Mancha. 
M. del Rosario García Huerta, David Rodríguez González, Lucía Soria Combadiera, Francisco Javier Morales Hervás

RODRÍGUEZ GONZÁLEZ, D.; ARCOS, M. C.; MOLINA, M.; ÁLVAREZ, H. (2016): La Prehistoria en el término municipal de Ciudad Real: características y evolución del poblamiento desde el Paleolítico hasta la Edad del Hierro, II Congreso Nacional "Ciudad Real y su provincia (F. Alía, J. Anaya, L. Mansilla, J. Sánchez, coords.), Ciudad Real, 75-105.

RODRÍGUEZ LÓPEZ-CANO, D.; PALENCIA GARCÍA, J. F. (2014): Urna de cerámica estampillada del Cerro de las Cabezas (Valdepeñas, Ciudad Real) aparecida en Madridejos (Toledo), Ex Officina Hispana: Cuadernos de la SECAH $5,13-14$
RUIZ RODRÍGUEZ, A.; NOCETE, F. (1981): Un modelo sincrónico para el análisis de la producción de cerámica ibérica estampillada del Alto Guadalquivir, CPUG 6, 355-383.

UROZ RODRÍGUEZ, H. (2012): Prácticas rituales, iconografía vascular y cultura material en Libisosa (Lezuza, Albacete). Nuevas aportaciones al Ibérico Final del Sudeste, Alicante.

VALOR, J. P; MATA, C.; FROCHOSO, R.; IRANZO, P. (2005): Las cerámicas con decoración impresa e incisa del territorio de Kelin (comarca de Requena- Utiel, Valencia), Sagvntvm-PLAV 37, 105-124.

VÉLEZ RIVAS, J.; PÉREZ AVILÉS, J. J. (1987): El yacimiento protohistórico del Cerro de las Cabezas, Oretum III, 168-196.

\section{ANEXO 1:}

Tabla completa de las cerámicas estudiadas: motivos y variantes

\begin{tabular}{|c|c|c|c|c|c|c|}
\hline $\begin{array}{l}\text { Motivo y } \\
\text { variantes }\end{array}$ & Sigla & $\begin{array}{c}\text { Forma del } \\
\text { Enmarque/geometría } \\
\text { del motivo }\end{array}$ & $\begin{array}{l}\text { Tipología del } \\
\text { motivo }\end{array}$ & Asociado a & $\begin{array}{l}\mathrm{N}^{o} \text { de } \\
\text { piezas }\end{array}$ & $\begin{array}{c}\text { Porcentaje } \\
\text { sobre el total }\end{array}$ \\
\hline \multicolumn{7}{|c|}{ TIPOA } \\
\hline & AL09-U13-SUP-34 & $\begin{array}{l}\text { Rectangular- } \\
\text { cuadrangular }\end{array}$ & $\begin{array}{l}\text { A.II. } \\
\text { Radial }\end{array}$ & $\begin{array}{l}\text { Decoración pintada } \\
\text { (Líneas horizontales) }\end{array}$ & 1 & 1,58 \\
\hline & AL02-U13-1-3 & $\begin{array}{l}\text { Rectangular- } \\
\text { cuadrangular }\end{array}$ & $\begin{array}{l}\text { A.II. } \\
\text { Radial }\end{array}$ & - & 1 & 1,58 \\
\hline 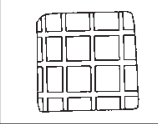 & AL10-U19-4-17 & $\begin{array}{l}\text { Rectangular- } \\
\text { cuadrangular }\end{array}$ & $\begin{array}{l}\text { A. III. } \\
\text { Reticulado }\end{array}$ & - & 1 & 1,58 \\
\hline Variante 1. & $\begin{array}{l}\text { AL05-U13-3-172 } \\
\text { AL06-U8-6-5-167 }\end{array}$ & & $\begin{array}{l}\text { A.V. } \\
\text { Líneas curvas } \\
\text { no cerradas }\end{array}$ & & 2 & 3,17 \\
\hline & & $\begin{array}{l}\text { Rectangular- } \\
\text { cuadrangular }\end{array}$ & & - & & \\
\hline Variante 2. & AL99-U7/8-1-10-1 & & & & 1 & 1,58 \\
\hline \begin{tabular}{|l|l|}
5 & 0 \\
10 & 0 \\
\end{tabular} & AL09-U13-1 & $\begin{array}{l}\text { Rectangular- } \\
\text { cuadrangular }\end{array}$ & $\begin{array}{l}\text { A.VII. } \\
\text { No } \\
\text { representativo }\end{array}$ & $\begin{array}{l}\text { Decoración pintada } \\
\text { (Líneas horizontales) }\end{array}$ & 1 & 1,58 \\
\hline 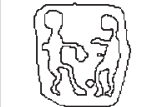 & AL12-U20-3-1 & $\begin{array}{l}\text { Rectangular- } \\
\text { cuadrangular }\end{array}$ & A. VIII. & & 1 & 1,58 \\
\hline
\end{tabular}


LAS CERÁMiCAS IBÉRICAS CON DECORACIÓN IMPRESA de Alarcos (CiUdAd REAL)

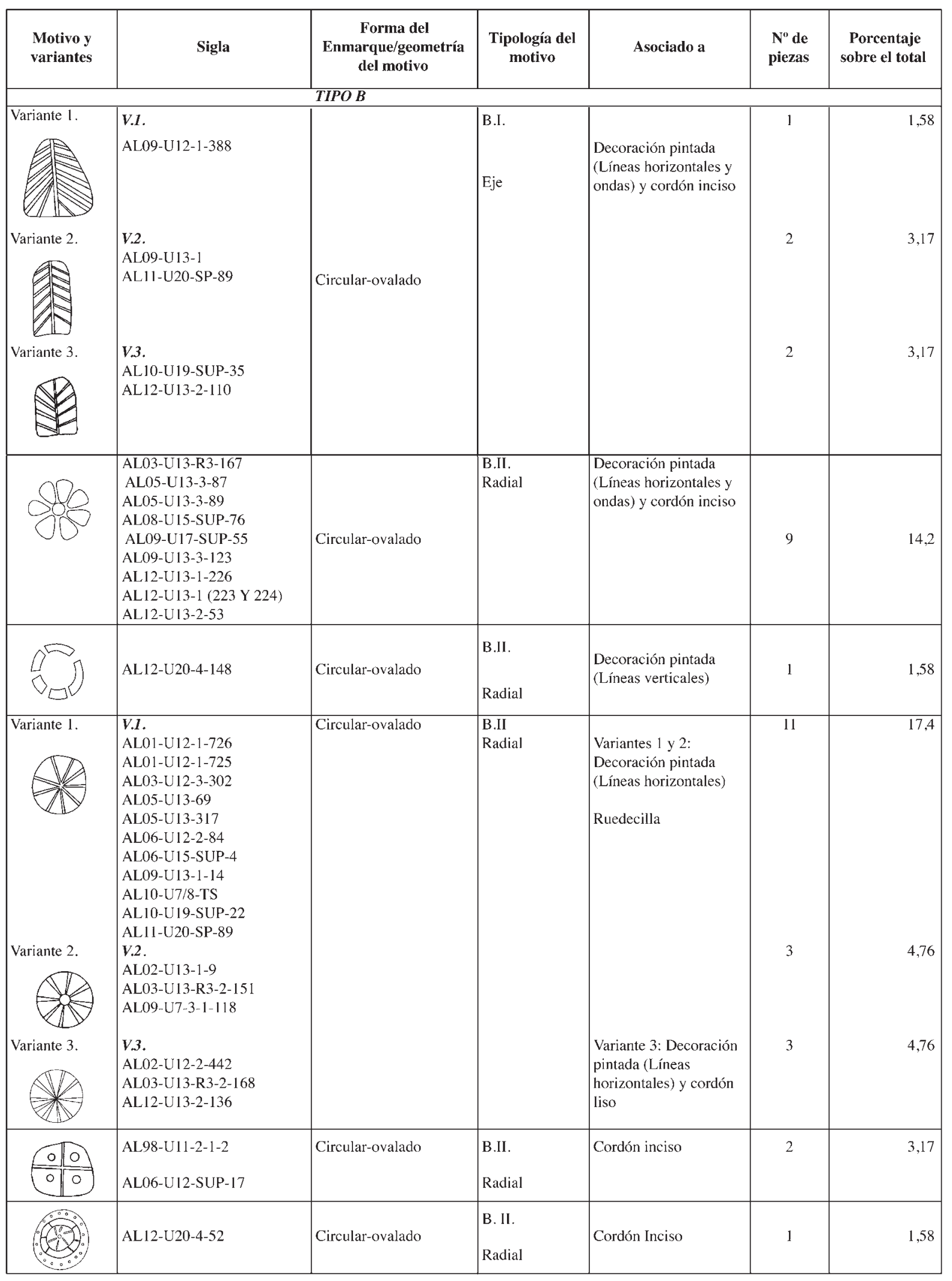


M. del Rosario García Huerta, David Rodríguez González, Lucía Soria Combadiera, Francisco Javier Morales Hervás

\begin{tabular}{|c|c|c|c|c|c|c|}
\hline $\begin{array}{l}\text { Motivo y } \\
\text { variantes }\end{array}$ & Sigla & $\begin{array}{c}\text { Forma del } \\
\text { Enmarque/geometría } \\
\text { del motivo }\end{array}$ & $\begin{array}{l}\text { Tipología del } \\
\text { motivo }\end{array}$ & Asociado a & $\begin{array}{l}N^{o} \text { de } \\
\text { piezas }\end{array}$ & $\begin{array}{l}\text { Porcentaje } \\
\text { sobre el total }\end{array}$ \\
\hline aro & $\begin{array}{l}\text { AL02-U12-2-27 } \\
\text { ALO5-U13-3-22 }\end{array}$ & Circular-ovalado & $\begin{array}{l}\text { B.III. } \\
\text { Reticulado }\end{array}$ & $\begin{array}{l}\text { Decoración pintada } \\
\text { (Líneas horizontales) }\end{array}$ & 2 & 3,17 \\
\hline Variante 1. & $\begin{array}{l}\text { V.I. } \\
\text { AL02-U13-1-2 } \\
\text { AL03-U7/8-U11-5 }\end{array}$ & Circular-ovalado & $\begin{array}{l}\text { B. IV. } \\
\text { Concéntrico }\end{array}$ & $\begin{array}{l}\text { Decoración pintada } \\
\text { (Líneas horizontales) }\end{array}$ & 6 & 9,52 \\
\hline Variante 2. & $\begin{array}{l}V .2 . \\
\text { AL05-U13-3-20 } \\
\text { AL05-U9-1-69 } \\
\text { AL06-U15-4-68 } \\
\text { AL11-U19-6-97 } \\
\text { AL04-U9-2-82 }\end{array}$ & & & & 1 & 1,58 \\
\hline $\begin{array}{l}\text { Variante } 3 . \\
\qquad(\text { (in) }\end{array}$ & $\begin{array}{l}\text { V.3. } \\
\text { AL97-U7/8-1-5-439 } \\
\text { AL04-U9-2-112 } \\
\text { AL09-U13-1-14 } \\
\text { AL05-U9-2-51 }\end{array}$ & & & & 4 & 6,3 \\
\hline Variante 4. & $\begin{array}{l}\text { V.4. } \\
\text { AL97-U7/8-1-5-439 }\end{array}$ & & & & 1 & 1,58 \\
\hline & AL05-U13-3-21 & Circular-ovalado & $\begin{array}{l}\text { B.V. } \\
\text { Líneas curvas } \\
\text { no cerradas }\end{array}$ & $\begin{array}{l}\text { Decoración pintada } \\
\text { (Líneas horizontales y } \\
\text { ondas) y cordón inciso }\end{array}$ & 1 & 1,58 \\
\hline & AL12-U20-4-52 & Circular-ovalado & $\begin{array}{l}\text { B.V. } \\
\text { Líneas curvas } \\
\text { no cerradas }\end{array}$ & & 1 & 1,58 \\
\hline & AL03-U13-R3-1 & Circular-ovalado & $\begin{array}{l}\text { B. VI. } \\
\text { Líneas } \\
\text { quebradas no } \\
\text { cerradas }\end{array}$ & $\begin{array}{l}\text { Decoración pintada } \\
\text { (Líneas horizontales y } \\
\text { segmentos) }\end{array}$ & 1 & 1,58 \\
\hline \multicolumn{7}{|c|}{ TIPOC } \\
\hline & AL08-U6-1-23 & Triangular & \begin{tabular}{|l} 
C. VII. \\
No \\
representativo
\end{tabular} & & 1 & 1,58 \\
\hline \multicolumn{7}{|c|}{ TIPO D } \\
\hline Quld & AL11-U20-SP-8 & $\begin{array}{l}\text { Forma adaptada al } \\
\text { motivo }\end{array}$ & $\begin{array}{l}\text { D.V. } \\
\text { Líneas curvas } \\
\text { no cerradas }\end{array}$ & & 1 & 1,58 \\
\hline$(\sqrt{5}$ & AL11-U19-7-61 & $\begin{array}{l}\text { Forma adaptada al } \\
\text { motivo }\end{array}$ & $\begin{array}{l}\text { D. } \mathrm{V} \text {. } \\
\text { Líneas curvas } \\
\text { no cerradas }\end{array}$ & $\begin{array}{l}\text { Decoración pintada } \\
\text { (Líneas horizontales) }\end{array}$ & 1 & 1,58 \\
\hline & & & & & Total: 63 & $100 \%$ \\
\hline
\end{tabular}


ANEXO 2:

\title{
ANÁlisis ARQUEOMÉTRICO DE LAS CERÁMICAS ESTAMPILlADAS DE AlarCoS (Ciudad Real)
}

\author{
DAVID GUIRAO POLO
}

Grupo Mineralogía Aplicada. Universidad de Castilla-La Mancha. David.Guirao@uclm.es

\section{MATERIALES Y MÉTODOS}

En el presente trabajo se ha analizado la composición química y mineralógica de cinco fragmentos de cerámicas estampilladas, con el objetivo de identificar si se trata de una producción local o alóctona, y aportar algunos datos sobre el proceso de elaboración de las cerámicas.

Las técnicas empleadas han sido: análisis de microscopía óptica (MO), difracción de rayos X (DRX) y fluorescencia de rayos $\mathrm{X}$ (FRX). Se ha realizado un tratamiento estadístico utilizando la base de datos (BD) de cerámicas ibéricas pintadas (IBC) de Alarcos, utilizando los siguientes elementos traza: $\mathrm{Sc}, \mathrm{Rb}, \mathrm{V}, \mathrm{Sr}, \mathrm{Ba}$, $\mathrm{Cr}, \mathrm{Y}, \mathrm{La}, \mathrm{Co}, \mathrm{Zr}, \mathrm{Ce}, \mathrm{Ni}, \mathrm{Th}, \mathrm{Cu}, \mathrm{Zn}, \mathrm{Nb}, \mathrm{Ga}, \mathrm{Pb}$ y Nd. La muestra A55 no ha sido analizada químicamente al no tener peso suficiente. El programa utilizado ha sido el r.project.

\section{RESULTADOS Y DISCUSIÓN}

En la tabla de la fig. 3 se presentan algunas de las características más destacables del conjunto de muestras. Todas las pruebas realizadas indican que el proceso de elaboración de estas cerámicas fue muy uniforme. En las imágenes captadas por el MO se observa la homogeneidad en la tonalidad de las pastas asalmonadas, en el número y distribución de las inclusiones no plásticas (cuarcíticas, calcáreas, feldespáticas y óxidos de hierro), en el proceso de cocción oxidante y en la porosidad de las mismas.

La composición mineralógica (DRX) de las 5 muestras es la misma (fig. 2). Los minerales de origen primario son el cuarzo $(\mathrm{Q})$, los filosilicatos (moscovita= Ms), los feldespatos potásicos (Kfs), la calcita (Cal) y el talco (Tal). La presencia de talco coincide con las 16 muestras del grupo

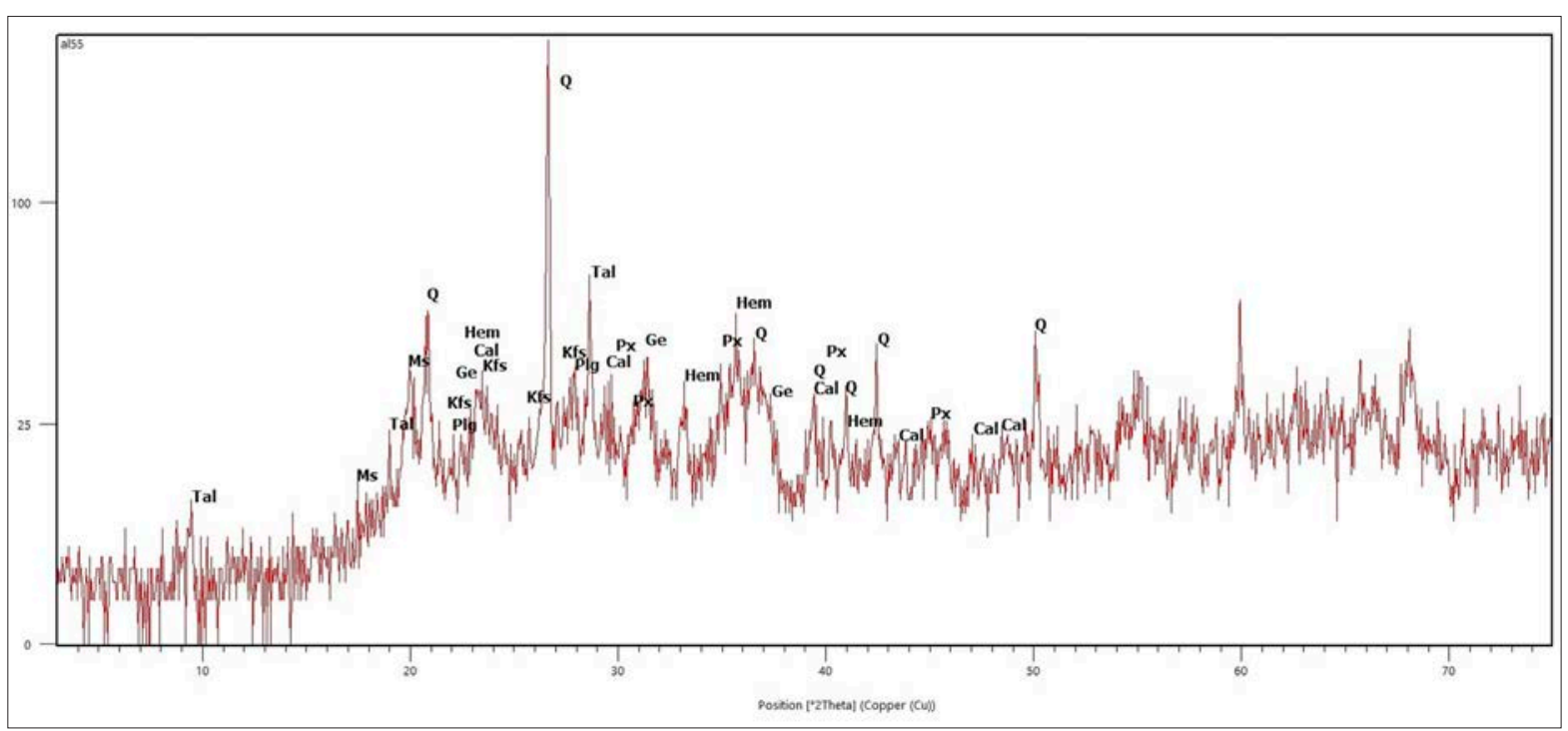

Fig. 1: Difractograma de A55. 


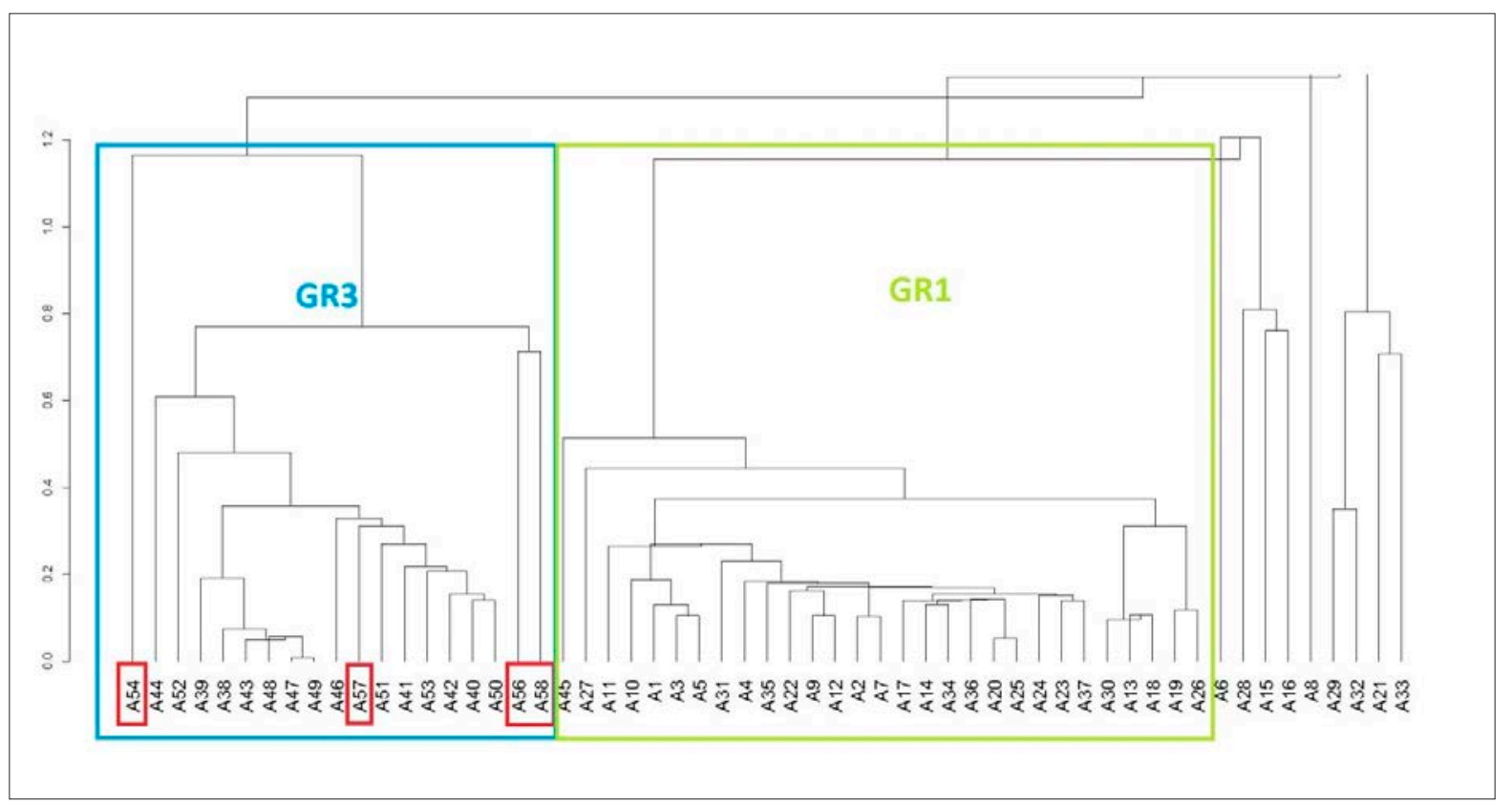

Fig. 2: Clúster análisis (Dendrograma) formado por 54 muestras de IBC de la BD de Alarcos y las cerámicas estampilladas A54, A56, A57 y A58 enmarcadas.

de referencia o grupo químico 3 (GR), recogidas todas en ellas dos viviendas (U20-4 y U13) próximas al gran almacén. Este mineral podría ser utilizado como desgrasante para contrarrestar la plasticidad de las arcillas y obtener unas pastas de color salmón homogéneas. Los minerales de cocción son la gehlenita $(\mathrm{Ge})$, los piroxenos (Px), las hematites (Hem) y las plagioclasas (Plg), aunque estos dos últimos podrían tener un origen primario e intensificarse durante la cocción. La existencia de picos bien definidos de gehlenita y piroxenos, minerales que se forman a partir de $\operatorname{los} 850^{\circ} \mathrm{C}$ y la no total descomposición de filosilicatos y calcita, permiten estimar una temperatura de cocción para las cinco muestras en el rango de los $900-950^{\circ} \mathrm{C}$.
Los resultados obtenidos en el análisis químico (FRX) confirman la uniformidad detectada en el estudio mineralógico. En la fig.1 (clúster análisis) las muestras A54, A56, A57 y A58 se unen al GR3 (A38-A53) corroborando su producción local. El GR1 está formado por 29 muestras procedentes del gran almacén. De las 58 muestras estudiadas, ocho se quedan al margen de los GR de Alarcos, por lo que podrían ser consideradas como producciones no locales. Las ocho muestras fueron recogidas también en el almacén, un espacio que por su funcionalidad de tratamiento y almacenaje de alimentos recibiría alimentos en continentes cerámicos procedentes de otros asentamientos de la zona. 


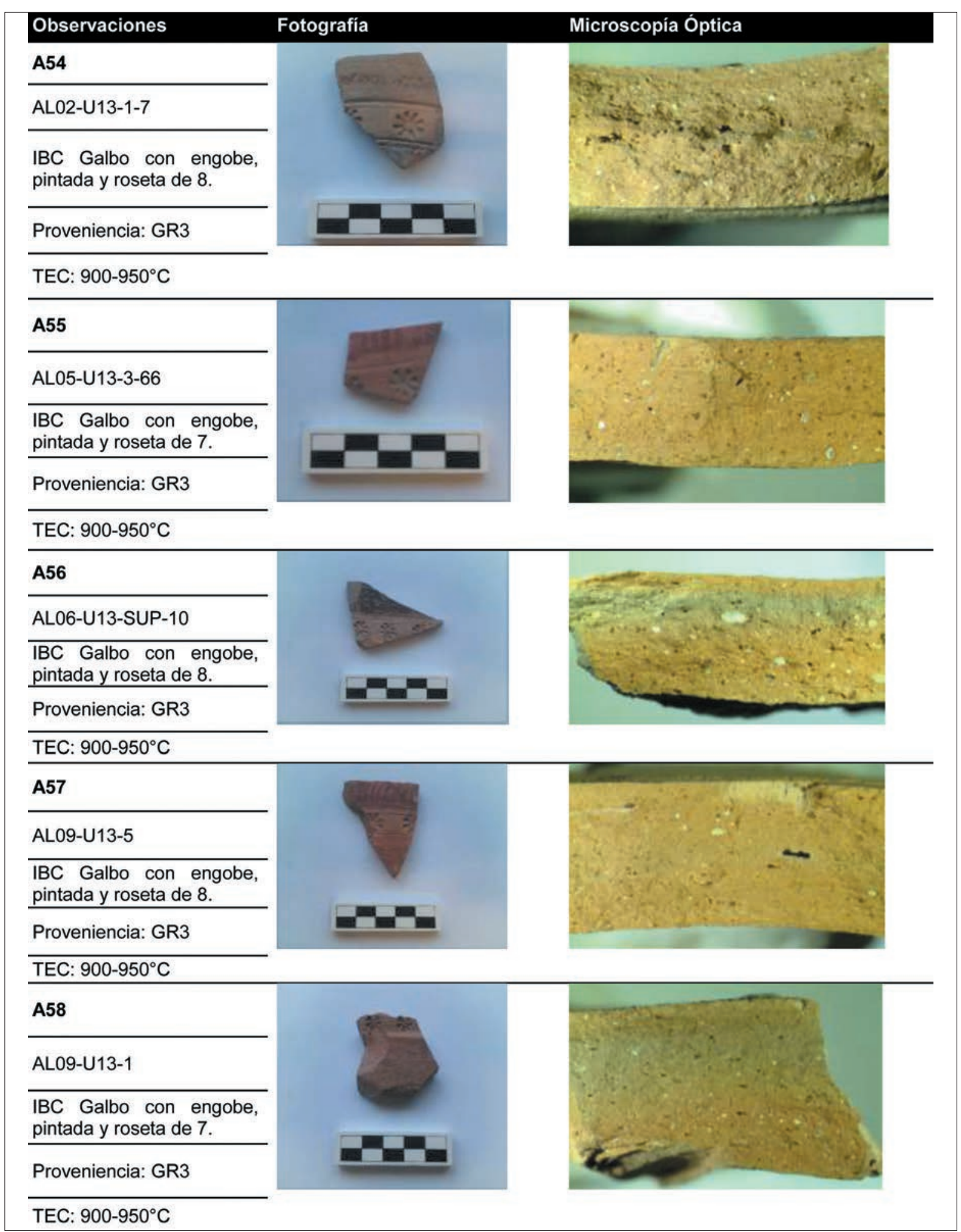

Fig. 3: Tabla-Resumen de las cinco muestras analizadas. Fotos e imágenes captadas con el MO. 